\title{
Sensitivity of high-temperature weather to initial soil moisture: a case study using the WRF model
}

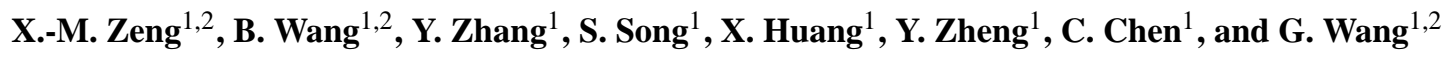 \\ ${ }^{1}$ College of Meteorology and Oceanography, PLA University of Science and Technology, Nanjing, Jiangsu, China \\ ${ }^{2}$ Key Laboratory for Mesoscale Severe Weather of Ministry of Education, Nanjing University, Nanjing, Jiangsu, China
}

Correspondence to: X.-M. Zeng (zen_xm@yahoo.com)

Received: 30 December 2013 - Published in Atmos. Chem. Phys. Discuss.: 9 May 2014

Revised: 18 August 2014 - Accepted: 20 August 2014 - Published: 16 September 2014

\begin{abstract}
Using a succession of $24 \mathrm{~h}$ Weather Research and Forecasting model (WRF) simulations, we investigate the sensitivity to initial soil moisture of a short-range hightemperature weather event that occurred in late July 2003 in East China. The initial soil moisture (SMOIS) in the Noah land surface scheme is adjusted (relative to the control run, CTL) for four groups of simulations: DRY25 $(-25 \%)$, DRY50 $(-50 \%)$, WET25 $(+25 \%)$ and WET50 $(+50 \%)$. Ten $24 \mathrm{~h}$ integrations are performed in each group.

We focus on $2 \mathrm{~m}$ surface air temperature (SAT) greater than $35^{\circ} \mathrm{C}$ (the threshold of "high-temperature" events in China) at 06:00 UTC (roughly 14:00 LT in the study domain) to analyse the occurrence of the high-temperature event. The 10-day mean results show that the 06:00 UTC SAT (SAT06) is sensitive to the SMOIS change; specifically, SAT06 exhibits an apparent increase with the SMOIS decrease (e.g. compared with CTL, DRY25 generally results in a $1{ }^{\circ} \mathrm{C}$ SAT06 increase over the land surface of East China), areas with $35^{\circ} \mathrm{C}$ or higher SAT06 are the most affected, and the simulations are more sensitive to the SMOIS decrease than to the SMOIS increase, which suggests that hot weather can be amplified under low soil moisture conditions. Regarding the mechanism underlying the extremely high SAT06, sensible heat flux has been shown to directly heat the lower atmosphere, and latent heat flux has been found to be more sensitive to the SMOIS change, resulting in an overall increase in surface net radiation due to the increased greenhouse effect (e.g. with the SMOIS increase from DRY25 to CTL, the 10day mean net radiation increases by $5 \mathrm{~W} \mathrm{~m}^{-2}$ ). Additionally, due to the unique and dynamic nature of the western Pacific subtropical high, negative feedback occurs between the regional atmospheric circulation and the air temperature in the
\end{abstract}

lower atmosphere while positive feedback occurs in the midtroposphere.

Using a method based on an analogous temperature relationship, a detailed analysis of the physical processes shows that for the SAT change, the SMOIS change affects diabatic processes (e.g. surface fluxes) more strongly than the adiabatic process of subsidence in the western Pacific subtropical high in the five groups of simulations. Interestingly, although diabatic processes dominate subsidence during the daytime and night-time separately, they do not necessarily dominate during the $24 \mathrm{~h}$ periods (e.g. they are dominant in the WET and CTL simulations only). Further, as the SMOIS decreases, the SAT06 increases, which is largely due to the reduced cooling effect of the diabatic processes, rather than the warming effect of subsidence.

Unlike previous studies on heatwave events at climate timescales, this paper presents the sensitivity of simulated short-term hot weather to initial soil moisture and emphasises the importance of appropriate soil moisture initialization when simulating hot weather.

\section{Introduction}

Under the background of global warming, heatwave events have occurred frequently worldwide, especially in the early 21 st century. As stated in a report by the World Meteorological Organisation, the first decade of the century was the hottest on record since modern measurements began circa 1850 (WMO, 2013). In the summer of 2003, Continental Europe was hit by a persistent abnormal heatwave during which the average summer temperature in most areas was 
$3{ }^{\circ} \mathrm{C}$ higher than that of the 30-year (1961-1969) average; over 35000 heat-related deaths were estimated across Europe (e.g. Larsen, 2003). In the same period, abnormal hightemperature weather also occurred in the regions south of the Yangtze River and South China (e.g. Lin et al., 2005; Yang and $\mathrm{Li}, 2005$; Zeng et al., 2011), resulting in increased daily mortalities (Tan et al., 2007). In the summer of 2010, persistent and abnormally hot weather occurred in eastern Europe and Russia, during which the maximum average regional temperature in western Russia was $8-10^{\circ} \mathrm{C}$ higher than the average summer temperature for the period of 2003-2009; the super-heatwave events in 2003 and 2010 likely surpassed the maximum summer temperature of the last 500 years over nearly half of Europe (Barriopedro et al., 2011; Lau and Kim, 2012). In early July 2012, over half of America was hit by a persistent heatwave for approximately 1 week, and record-high temperatures were set in many places (Donat et al., 2013). These high-temperature and heatwave events not only directly threaten human health and safety but also cause droughts and forest fires, which pose serious hazards to the entire ecological system and severely impact electrical power, transportation, and so forth (Tan et al., 2007; Zeng et al., 2011).

In recent decades, researchers have investigated the causes of the formation and persistence of high-temperature and heatwave events from various aspects (e.g. Wolfson et al., 1987; Lyon and Dole, 1995; Lin et al., 2005; Fischer et al., 2007; Zeng et al., 2011; Lau and Kim, 2012). Landatmosphere interactions are known to have an important impact on weather and climate (e.g. Shukla and Mintz, 1982; Pielke, 2001; Koster et al., 2004; Guo et al. 2011). Specifically, the influence of soil moisture anomalies on hightemperature events has been widely investigated (Wolfson et al., 1987; Ferranti and Viterbo, 2006; Fischer et al., 2007; Fennessy and Kinter, 2011; Lau and Kim, 2012). For example, Wolfson et al. (1987) used a series of general circulation model experiments to explore the roles of sea surface temperature anomalies of the North Pacific, soil moisture anomalies of the American continent and solar radiative forcing in the maintenance and weakening of the extreme heatwave of the United States in the summer of 1980; in the case of a warm and dry environment, low soil moisture was beneficial for the maintenance of the event. In studying the 2003 heatwave in Europe, Fischer et al. (2007) indicated that during the heatwave, the soil moisture was extremely low, which substantially reduced latent cooling (latent heat flux) and greatly increased the surface temperature anomaly; their regional climate model sensitivity simulations showed that soil moisture played a key role in the partitioning of net radiation into latent and sensible heat fluxes and in the evolution of the heatwave. Positive feedback was identified between soil moisture, atmospheric circulation, and temperature based on the summer anomalies of geopotential heights and air temperature in the troposphere. Hirschi et al. (2011) analysed observational indices and found a relationship between soil-moisture deficit and summer hot extremes in southeastern Europe; the results were compared with climate model simulations. Using an atmospheric general circulation model, Fennessy and Kinter (2011) emphasised the important roles of both the warm local sea surface temperature and the dry local soil in intensifying the 2003 European heatwave. Using two long-term Weather Research and Forecasting model (WRF) simulations with and without soil moisture-atmosphere interactions to evaluate the influence of the land-atmosphere coupling on a summer heatwave in China, Zhang and Wu (2011) found that the land-atmosphere coupling amplifies hot extremes over China, especially in most areas of eastern and southeastern China; the increase was statistically significant. Regarding the summer 2010 Russian heatwave, Lau and Kim (2012) demonstrated that there was positive feedback between the extratropical atmospheric blocking pattern and an underlying extensive land region with below-normal soil moisture, which amplified the heatwave. In most of these investigations, weather or climate models were used for continuous integration for a relatively long time (e.g. seasons) to explore the influence of soil moisture on the heatwave events. It was concluded that precedent low soil moisture or low soil moisture during the events was beneficial for the generation, maintenance or enhancement of heat waves.

There have been many numerical studies concerning the effect of different land surface schemes or initial model conditions on short-range weather (e.g. Xue et al., 2001; Holt et al., 2006; Lei et al., 2008; Sun et al., 2012). Many of these studies highlighted the importance of land surface processes on heavy rainfall events. However, there has been relatively little research focusing on the role of soil moisture in the formation or development of high-temperature weather at short timescales (e.g. $24 \mathrm{~h}$ ). This research is important for two reasons. First, soil moisture is a key physical quantity in land-atmosphere interactions - e.g. in the Global Land Atmosphere Coupling Experiment (GLACE), soil-moistureprecipitation coupling strength and soil moisture initialisation in numerical models were the research focuses in the two phases of the project (Koster et al., 2006; Guo et al., 2011) (these were also focuses in the mentioned literature). Second, the role of soil moisture might differ at different timescales and affect simulation results. In this regard, relatively longterm soil moisture effects have received attention. For example, observations have shown that in many areas, soil moisture anomalies can persist for weeks to months (e.g. Vinnikov and Yeserkepova, 1990; Seneviratne et al., 2006), and a large number of studies have quantified the effect of soil moisture initialisation on the performance of sub-seasonal to seasonal climatology forecasts. Soil moisture anomalies and soil moisture differences have been shown to impact climate variability and even substantially affect forecast accuracy by modifying surface sensible and latent heat fluxes, as well as atmospheric circulations (e.g. Beljaars et al., 1996; Fennessy and Shukla, 1999; Viterbo and Betts, 1999; Zeng et al., 2003; 
Koster et al., 2004; Douville, 2010; Guo et al., 2012). As indicated by Fennessy and Shukla (1999), the strength of the impact of the initial soil wetness differences was dependent on several factors, such as the areal extent and magnitude of the initial soil wetness difference and the persistence of the soil wetness difference. In this context, the impact of the initial soil wetness difference on numerical modelling, using a coupled model, also depends on the simulation lengths or the timescales of interest.

Therefore, regarding short-range high-temperature weather or heatwave simulations, the following questions arise: (1) Are short-range (e.g. $24 \mathrm{~h}$ ) simulations sensitive to the change in soil moisture and, if so, to what extent? (2) What is the mechanism responsible for the change in simulated variables (e.g. air temperature) induced by the initial soil moisture? Moreover, what is the relative importance of the physical processes (e.g. surface heat transfer via sensible and latent heat fluxes and atmospheric processes via advection and convection) that affect the simulated temperature for continental China? The answers to these questions can enhance our understanding on the influence of soil moisture and can help us to improve the accuracy of high-temperature weather forecasts.

The objective of this paper is to quantify and explain the sensitivity of high-temperature weather to initial soil moisture by answering the above questions. Hence, using different soil moisture initialisations in the Noah land surface scheme in the WRF model, we perform sensitivity experiments to simulate the temperature change and related quantities (e.g. sensible and latent heat fluxes, radiative fluxes and geopotential heights) for the East China high-temperature event of late July 2003. Therefore, in Sect. 2 of this paper, we describe the climate background of the high-temperature event (e.g. anomalies in the $500 \mathrm{hPa}$ geopotential heights and surface temperatures) and the experimental design. In Sect. 3, the simulation results are analysed using a comparison among the simulated surface air temperature (SAT) results and observations to quantify sensitivity and further explain how and to what extent the physical processes (e.g. surface heat transfer, atmospheric advection and convection) affect the soil moisture-induced temperature changes. Finally, Sect. 4 presents a summary and conclusions of the research.

\section{Methods and data}

\subsection{Experimental design}

\subsubsection{Climate background of the simulation period}

Previous studies have shown that persistent, strong anomalies and an exceptionally westward position of the western Pacific subtropical high were the prevalent causes of the continuous high-temperature weather in southern China (mainly in southeastern continental China; see area D3 in Fig. 1a) in
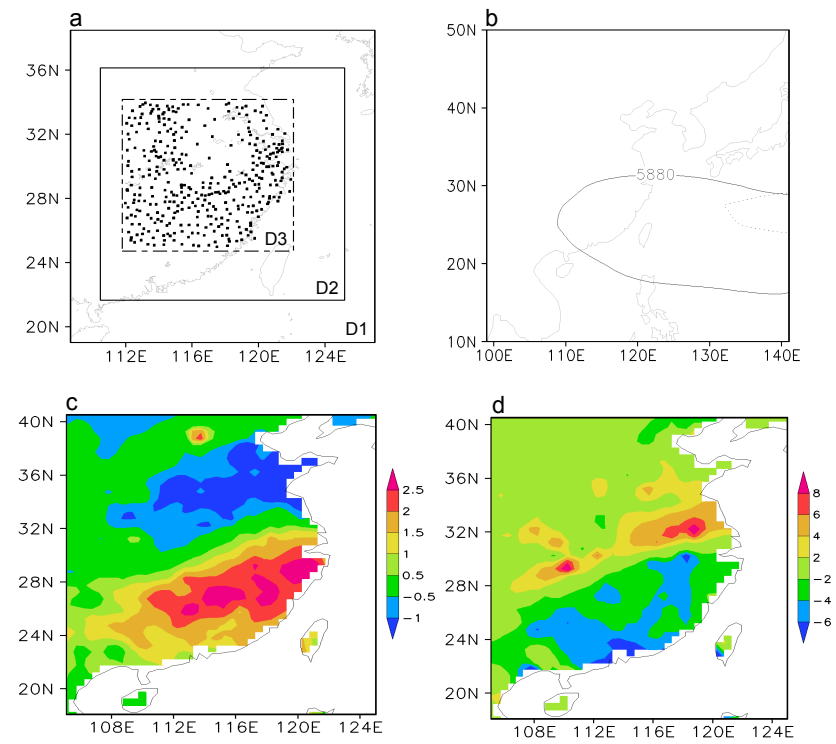

Figure 1. The study areas and climatology. (a) The model domain, where the D1 and D2 sub-areas are the large and nested areas, respectively, while D3 is the "core" region of southeastern China, where the extremely high temperatures occurred (the meteorological stations are marked by dots). (b) The $500 \mathrm{hPa} 5880 \mathrm{gpm}$ contours of the climatological averages for July 2003 (solid line) and the base period (1971-2000; dashed line). (c) The July 2003 SAT anomaly, i.e. departures from the base period (1971-2000) average (unit: ${ }^{\circ} \mathrm{C}$ ). (d) Same as (c) but for precipitation (units: $\mathrm{mm} \mathrm{d}^{-1}$ ).

the summer of 2003 (Lin et al., 2005; Yang and Li, 2005; Zeng et al., 2011). Shown in Fig. 1b, the subtropical high in July 2003 exhibited a west-east distribution that spanned $15^{\circ}$ of latitude, where the westward extent of the ridge of the $5880 \mathrm{gpm}$ (geopotential metres; quantitatively, $1 \mathrm{gpm}$ is very close to $1 \mathrm{~m}$ in the troposphere) contour was west of $110^{\circ} \mathrm{E}$. Compared to the multi-year (1971-2000) climate, both the north-south extent and area of the western Pacific subtropical high were larger for this event, the position was abnormally $20^{\circ}$ west and the intensity was stronger. In the summer, East China was persistently controlled by the much stronger westward ridge of the subtropical high, with weaker winds and more sunny days, which result in exceptionally hot weather.

Figure 1c and d present the anomalies of the SAT and precipitation, respectively, that occurred in July 2003 for the region; here, the climatological data set of Willmott et al. (1998) was applied. During the period, most areas south of the Yangtze River had an average SAT $1.5^{\circ} \mathrm{C}$ higher than the multi-year average, while the SAT in the Huaihe River basin $\left(30-36^{\circ} \mathrm{N}, 112-121^{\circ} \mathrm{E}\right)$ was $1{ }^{\circ} \mathrm{C}$ lower than normal (Fig. 1c). In the regions to the south of the Yangtze River, the precipitation was generally more than $2 \mathrm{~mm} \mathrm{~d}^{-1}$ below normal, or $4 \mathrm{~mm} \mathrm{~d}^{-1}$ below normal for half of the area (Fig. 1d). However, there was substantially more precipitation in the Yangtze River and Huaihe River basins (Fig. 1d). 
From the distribution of day-to-day SATs (not shown), the high-temperature climate in southern China, with $35^{\circ} \mathrm{C}$ or higher daily maximum SATs, lasted for over 1 month (over 2 months in some areas). The daily maximum SATs in July from the middle and lower reaches of the Yangtze River to South China were as high as $38-40^{\circ} \mathrm{C}$; the values even reached $40-43{ }^{\circ} \mathrm{C}$ in some areas of the southeastern coastal region, especially in late July, which was the hottest period of the summer according to 10-day moving averages of SAT over the study area (Zeng et al., 2011). Record high temperatures, heatwave extents and heatwave durations were set.

\subsubsection{WRF and the experiment schemes}

We investigated the sensitivity of the temperature simulations to initial soil moisture using the Advanced Research WRF model (Version 3; Skamarock et al., 2008). As a community mesoscale model developed by the National Center for Atmospheric Research and other research institutions, WRF contains key dynamic features, such as fully compressible nonhydrostatic equations, complete Coriolis and curvature terms, and includes many advanced physical parameterisation schemes. The schemes adopted in this study include the microphysics scheme of Lin et al. (1983), the BettsMiller-Janjic subgrid-scale cloud scheme (Janjic, 1994), the Rapid Radiation Transfer Model long-wave radiation scheme (Mlawer et al., 1997), the Goddard short-wave radiation scheme (Chou and Suarez, 1994), the Monin-Obukhov surface layer scheme (Hong and Pan, 1996), the Yonsei University (YSU) boundary layer parameterisation scheme (Hong et al., 2006), and the Noah land surface scheme (Chen and Dudhia, 2001; Ek et al., 2003). Through the coupling of the land surface and atmospheric boundary layer schemes, WRF accounts for land-atmosphere interactions, e.g. soil-moistureair-temperature feedbacks.

Two-way nesting is used in the simulations. The simulation domain is centred at $\left(29^{\circ} \mathrm{N}, 117.5^{\circ} \mathrm{E}\right)$, with $60 \times 70$ grid points and $30 \mathrm{~km}$ spacing for the large domain (D1) and $127 \times 145$ grid points and $10 \mathrm{~km}$ spacing for the small domain (D2) (Fig. 1a). The vertical resolution is a nonuniform 31 layers with $50 \mathrm{hPa}$ set as the top of the model. In late July 2003, extremely high temperatures mainly occurred over the areas south of the Yangtze River in eastern China (i.e. East China, denoted as area "D3" within area "D2" in Fig. 1a). Except as otherwise stated, the statistical areal averages involved in the following analysis are the average values of the land component of area D3.

Similar to Zeng et al. (2011), the hottest late July period is the focus of this paper. The initial fields of the simulations are selected from 06:00 UTC on 20 July through 06:00 UTC on 29 July 2003 (at an interval of $24 \mathrm{~h}$ ), i.e. ten $24 \mathrm{~h}$ integrations are performed with a suite of model setups. We choose $24 \mathrm{~h}$ as the integration length because initial soil moisture is relatively less modified at this timescale of short-range weather. Subsequently, each integration is labelled with the ending time of the experiment; e.g. "D21" represents the simulation with the integration period from 06:00 UTC on 20 July 2003 to $06: 00$ UTC on 21 July 2003.

To investigate the sensitivity of the short-range hightemperature weather simulation to soil moisture, the initial soil moisture fields are treated as follows. First, the initial field of the total volumetric soil moisture content (hereafter SMOIS) is modified at each grid point; correspondingly, the values for each soil layer are modified. Second, on the basis of using the analysis data to perform ten $24 \mathrm{~h}$ integrations (i.e. the control run, or the CTL group of simulations) for late July and following Fischer et al. (2007), sensitivity experiments are conducted with the modified initial soil moisture, i.e. the four groups of simulations (WET50, WET25, DRY50 and DRY25) are conducted with the initial moisture content changes of $+50,+25,-50$ and $-25 \%$, respectively, relative to CTL. Thus, the $24 \mathrm{~h}$ simulations for a specific date (e.g. the D21 simulation) have five initial fields of soil moisture; in total, 50 simulations are conducted. Meanwhile, because the SMOIS values range from 0 to 1 (the value of 1 represents the land cover type of inland water), when the first-guest value of the SMOIS at a grid point is larger than the saturated value in the sensitivity simulations, the saturated value is set as the initial value for the integrations. Therefore, the SMOIS values for the inland water remain unchanged. As an example, Fig. 2 presents the surface soil moisture fields at 06:00 UTC on 20 July 2003 for the initial values in the D21 simulations. In Fig. 2a, except for the large inland water bodies (e.g. the Yangtze River, Taihu Lake and Poyang Lake), the soil moisture contents are generally less than $0.5 \mathrm{~m}^{3} \mathrm{~m}^{-3}$. In this case, the WET25 and WET50 soil moisture contents at the grid points can be increased by 25 and $50 \%$, respectively, except for a few grids that approach saturation (Fig. 2d and e).

Once the initial and boundary conditions are defined, according to the WRF formulations, both the land and atmospheric variables (e.g. atmospheric wind speeds, pressure, temperature, geopotential height, soil temperature and soil moisture), as well as the surface fluxes (e.g. radiative, sensible heat and latent heat fluxes), vary over time during the model integrations; these simulation results are used for the analysis.

It should be noted that there is no unified definition or standard of "heatwave" events. For example, the National Weather Service considers the effects of temperature and relative humidity, and an excessive heat warning is issued by the agency when daytime heat index values are expected to reach $40.5^{\circ} \mathrm{C}$ or above for two consecutive days or when the values are expected to exceed $46^{\circ} \mathrm{C}$ for any length of time (Kalkstein et al., 1996). For the Euro-Mediterranean region, Stefanon et al. (2012) presented a method for defining and classifying heat waves in which the events are grouped into six classes. In China, based on climate and environmental characteristics, high-temperature weather is classified into three levels in the context of daily maximum SAT, i.e. high temperature $\left(\geq 35^{\circ} \mathrm{C}\right)$, dangerously high temperature $\left(\geq 38^{\circ} \mathrm{C}\right)$, 

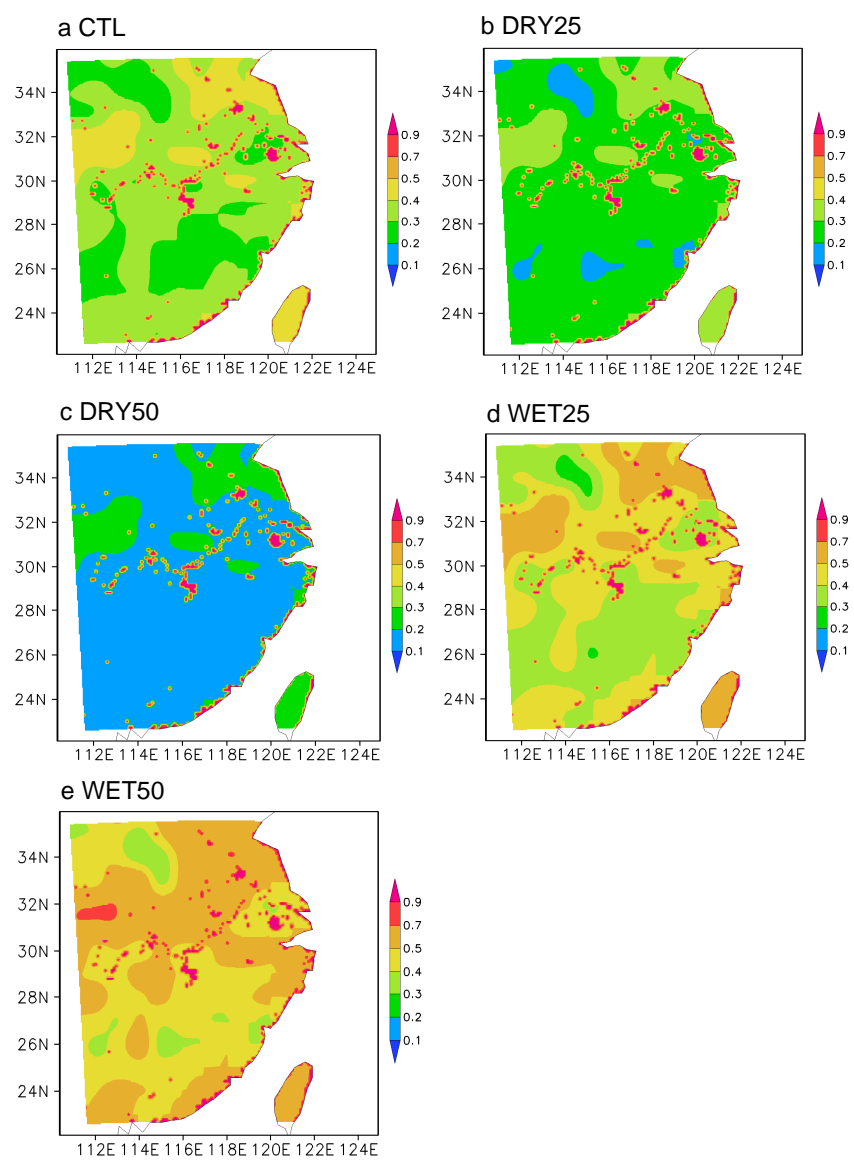

Figure 2. The initial surface soil moisture fields at 06:00 UTC 20 July 2003 in the D21 simulations (units: $\mathrm{m}^{3} \mathrm{~m}^{-3}$ ).

and intensely hazardous high temperature $\left(\geq 40^{\circ} \mathrm{C}\right.$ ) (Zhang et al., 2006). Because the SAT generally approaches the daily maximum value at approximately 14:00 Beijing Time (i.e. 06:00 UTC) in southeastern China (especially in summer when the weather is persistently hot), following Zeng et al. (2011), we assume that the SAT at 06:00 UTC (SAT06) is representative of the daily maximum SAT. According to observations (not shown), the $35^{\circ} \mathrm{C}$ or higher daily maximum SAT most prominently occurred in late July 2003 over southeastern China. In the context of the high-temperature classification in China, to investigate the sensitivity of simulated hot weather to initial soil moisture, we therefore focus on SAT06 results and related quantities for the study period of late July 2003, with an integration length of $24 \mathrm{~h}$ for each simulation.

\subsection{The data}

The meteorological initial and lateral boundary conditions for the WRF model, including the data of the soil moisture for CTL, are derived from the National Centers for Environmental Prediction (NCEP) Final (FNL) Operational Global Analysis data ( $1^{\circ}$ by $1^{\circ}$ resolution) prepared opera- tionally every six hours (00:00, 06:00, 12:00 and 18:00 UTC; http://rda.ucar.edu/datasets/ds083.2/). The FNL analysis data are from the Global Data Assimilation System that continuously collects observational data for many analyses; the data are produced with the same model in the NCEP Global Forecast System (GFS), which is a global spectral data assimilation and forecast model system (e.g. Whitaker et al., 2008). The data are prepared approximately an hour after the GFS is initialised because such a delay facilitates the use of more observational data. The GFS also uses the FNL data from the previous $6 \mathrm{~h}$ cycle as part of its initialisation. Moreover, the data set is also recommended for use in WRF for mesoscale weather simulations (http://www.dtcenter.org/ wrf-nmm/users/downloads/input_data.php).

To validate the temperature (i.e. SAT06) simulations, conventional observational data from the meteorological stations are used. Shown in Fig. 1a, 369 stations are located in the core region of East China.

\subsection{Analysis of physical processes}

We mainly focus on the change in air temperature due to the modified SMOIS. The temporal change in air temperature is governed by the partial differential equation that is derived from the first law of thermodynamics, i.e.

$\frac{\partial T}{\partial t}=-\boldsymbol{V} \cdot \nabla T-w\left(\gamma_{\mathrm{d}}-\gamma\right)+H_{\mathrm{t}}$,

where $\boldsymbol{V}$ represents the horizontal wind vector, $w$ is the vertical velocity, $\gamma_{\mathrm{d}}$ and $\gamma$ are the atmospheric temperature lapse rate and the dry adiabatic lapse rate, respectively, and $H_{\mathrm{t}}$ is the diabatic heating term. We let

$$
\begin{aligned}
& T_{\mathrm{t}}=\int_{t} \frac{\partial T}{\partial t} \mathrm{~d} t, \\
& \mathrm{ADV}=-\int_{t} V \cdot \nabla T \mathrm{~d} t, \\
& \mathrm{CON}=-\int_{t} w\left(\gamma_{\mathrm{d}}-\gamma\right) \mathrm{d} t
\end{aligned}
$$

and

$Q_{\mathrm{t}}=\int_{t} H_{\mathrm{t}} \mathrm{d} t$

represent integral terms for local temperature changes, advection, convection, and diabatic effects, respectively. Then, Eq. (1) can be rewritten as

$T_{\mathrm{t}}=\mathrm{ADV}+\mathrm{CON}+Q_{\mathrm{t}}$.

Thus, there are three factors (terms; units are in kelvin) that influence $T_{\mathrm{t}}$ in the right-hand side of Eq. (2): the first term, $\mathrm{ADV}$, means that warm advection causes the increase of the 

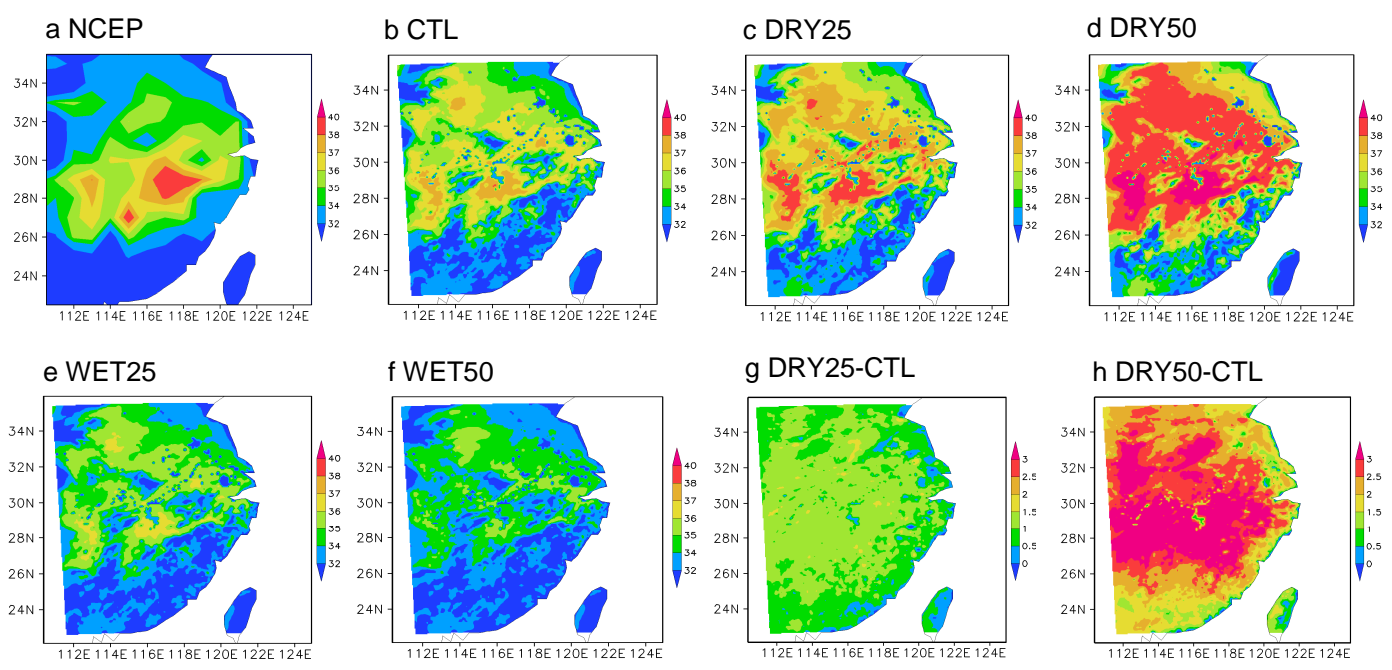
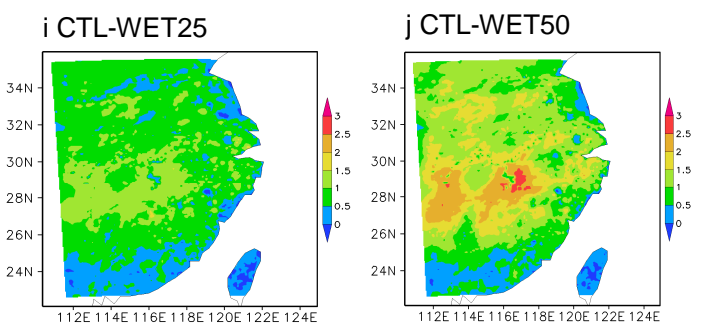

Figure 3. The spatial distributions of the 10-day mean SAT06 in the simulations (unit: ${ }^{\circ} \mathrm{C}$ ).

local temperature and vice versa; the second term, $\mathrm{CON}$, suggests that under stable stratification $\left(\gamma_{\mathrm{d}}-\gamma>0\right)$, ascending motion results in adiabatic cooling in the lower atmosphere and vice versa, while the situation is opposite under unstable stratification $\left(\gamma_{\mathrm{d}}-\gamma<0\right)$; and the third term, $Q_{\mathrm{t}}$, includes the diabatic influence of radiation, turbulent exchange and condensation processes, among others. Except for $Q_{\mathrm{t}}$, the other three terms of Eq. (2) can be calculated by the simulation outputs; therefore, $Q_{\mathrm{t}}$ can be obtained. Thus, the relative contributions of the factors to air temperature changes can also be examined.

Because there are few $2 \mathrm{~m}$ meteorological quantities in the model outputs, it is unable to calculate directly all of the terms in Eq. (2). Therefore, we utilise the analogous relationship between air temperature at $2 \mathrm{~m}$ and that at the lowest model level, where the model outputs are adequate (see Sect. 3.2.4), to explain the extent to which the $2 \mathrm{~m}$ temperature is affected by the physical processes.

\section{Results and discussion}

\subsection{Quantifying the sensitivity: preliminary results of temperature}

Because all the model settings and boundary and initial conditions, except the initial soil moisture content, are the same in the simulations, the differences between the simulations are caused by the different initial soil moisture contents. In addition, to examine the overall influence of the different initial soil moisture contents on the short-range hightemperature simulations for late July 2003, following Xue et al. (2001) and Zeng et al. (2011), we use the 10-day means of the simulated results in the following sections to investigate the event climatologically and systematically. Therefore, in this section, we preliminarily analyse the soil moisture-induced differences in the 10-day mean SAT06 values of the simulations.

\subsubsection{Spatial distribution}

As discussed above, the spatial SAT06 distributions are approximately the maximum SAT values over East China and the occurrence of the hottest weather during the study period. Figure 3 provides the average distributions of the 10day mean SAT06 for the simulations. The central position, range and strength of the high temperature simulated in the CTL run (Fig. 3b) are basically consistent with those in the NCEP FNL analysis field (Fig. 3a), i.e. the areas with $35^{\circ} \mathrm{C}$ or higher SATs are located within $26-32^{\circ} \mathrm{N}$ (the central part of the continental study area). The central positioning of the high values is well simulated. Nevertheless, the simulated high-temperature (above $35^{\circ} \mathrm{C}$ ) area is slightly larger and more northward than the analysis data. 
Compared with CTL, changing the initial soil moisture can substantially change the simulation results. For instance, in contrast to CTL (Fig. 3b), the central positions of the high temperature of SAT06 in DRY25 (Fig. 3c) and DRY50 (Fig. 3d) remain basically unchanged, but the range and intensity of the simulated high temperature are apparently increased. CTL produces a simulated maximum temperature of approximately $37^{\circ} \mathrm{C}$, with a relatively small area that has higher values. However, the maximum DRY25 temperature is higher than $38^{\circ} \mathrm{C}$ (i.e. dangerously high temperature), and the total area with $37^{\circ} \mathrm{C}$ or higher temperatures covers most of the CTL areas above $35^{\circ} \mathrm{C}$. The maximum temperature of DRY50 exceeds $40^{\circ} \mathrm{C}$, and the dangerously high temperature covers much of the area north of $26^{\circ} \mathrm{N}$. Clearly, a decrease in SMOIS corresponds to an increase in the simulated SAT06. Additionally, compared with CTL (Fig. 3b), the high temperature ranges and intensities in WET25 (Fig. 3e) and WET50 (Fig. 3f) obviously decrease, i.e. WET25 produces a maximum temperature of $\sim 36^{\circ} \mathrm{C}$, with a relatively small area above $35^{\circ} \mathrm{C}$ (SAT06), and WET50 only produces a maximum of $\sim 35^{\circ} \mathrm{C}$, with a very small area above $35^{\circ} \mathrm{C}$ (SAT06); thus, almost no high temperatures are simulated in the entire domain. In previous climate studies, regions with intermediate soil moisture have been found to be sensitive to soil-moisture-precipitation coupling (e.g. Koster et al., 2004). Based on regional climate model simulations for the 2003 European heatwave, Fischer et al. (2007) suggested that the soil moisture sensitivity was low in dry (near wilting point, e.g. DRY50 in their simulations) and wet (near field capacity, e.g. WET50) soil moisture conditions, and the sensitivity was high in intermediate soil moisture conditions. Unlike Fischer et al. (2007), we adopt WRF for shortrange weather simulations. Despite the further changes in the SMOIS, the model is unable to simulate values near the wilting point or field capacity for the overall study domain within $24 \mathrm{~h}$ (i.e. the total soil moisture does not change much at short timescales compared to long climate simulations with persistent prolonged modifications to soil moisture in heatwave events; see Sect. 3.2 for soil moisture variations); therefore, the SMOIS-induced sensitivity is high, at least for the heatwave development in the short range. Specifically, the above results suggest that with the SMOIS increase, the simulated SAT06 clearly decreases, even in some dry or wet soil moisture conditions. Meanwhile, with the SMOIS change, the SAT in the lower troposphere (e.g. $850 \mathrm{hPa}$ ) presents a change similar to the SAT06 (not shown). All of these results show that the high-temperature simulations with a short-term ( $24 \mathrm{~h})$ integration length are very sensitive to the change in initial soil moisture.

To assess the influence of the SMOIS change, further comparisons are made between CTL and the sensitivity simulations (Fig. 3g-j). Compared with CTL, DRY25 presents a SAT06 increase of more than $1{ }^{\circ} \mathrm{C}$ over most of the land areas (Fig. 3g), while the SAT06 in DRY50 rises more than $2{ }^{\circ} \mathrm{C}$ (generally) and $4{ }^{\circ} \mathrm{C}$ (maximally) over land (Fig. 3h). In
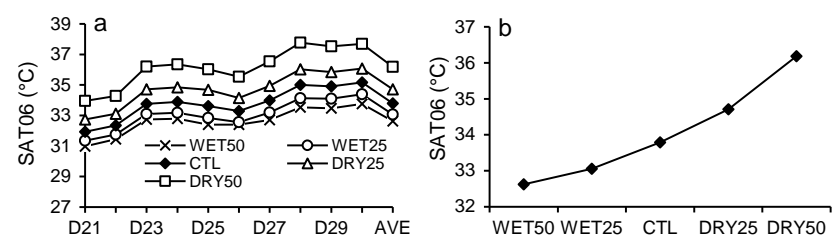

Figure 4. The average SAT06 values for area D3 in the simulations. (a) The values as changed with the individual simulations with an average (AVE) for each group of simulations. (b) The 10-day means as changed with the five groups of simulations.

contrast, WET25 reduces the temperature in most areas by more than $0.5^{\circ} \mathrm{C}$ (Fig. 3i), while WET50 reduces the temperature by more than $1^{\circ} \mathrm{C}$, with a maximum decrease greater than $2{ }^{\circ} \mathrm{C}$ (Fig. 3j). For a given sensitivity simulation, the amplitude of the temperature change differs in different areas; these changes are closely related to the local forcings of the surface energy balance, such as the sensible and latent heat fluxes (see Sect. 3.2). By comparing the four groups of sensitivity simulations with CTL, it is found that the magnitude of the temperature increase in DRY50 (DRY25) is greater than that in WET50 (WET25); therefore, the higher sensitivity of the simulated SAT06 is induced by lower soil moisture. In addition, the area with the largest SAT06 change is found over/around the area with temperatures above $35^{\circ} \mathrm{C}$. All of these findings indicate that the change in the initial soil moisture has a very large influence on the SAT06 simulation, or on the development of the short-range $(24 \mathrm{~h})$ extremely high temperature weather.

Figure 4 presents the average SAT06 values for area D3 in the simulations. In agreement with the above results, the higher soil moisture simulations produce lower area-averaged SAT06 for each simulation (Fig. 4a). Notably, the magnitude of the SAT06 increase from DRY25 (25\% SMOIS decrease) to DRY50 (50\% SMOIS decrease) is larger than the magnitude of the SAT06 decrease from WET25 (25\% SMOIS increase) to WET50 (50\% SMOIS increase). This result is consistent with the conclusions in previous climate studies (e.g. Fischer et al., 2007; Zhang and $\mathrm{Wu}, 2011$ ), i.e. because low soil moisture strongly reduces latent cooling, the surface temperature anomalies or heat waves are amplified. Our results show that during the $24 \mathrm{~h}$ integrations, the high-temperature simulation is more sensitive to the decrease in soil moisture than to the increase. The results are easily explained as follows: the lower thermal inertia induced by lower soil moisture leads to higher temperatures under given energy forcings. Figure $4 \mathrm{~b}$ further presents the nonlinear changes in the 10-day mean SAT06 in area D3 for the five groups of simulations; the WET25-WET50, CTLWET25, DRY25-CTL and DRY50-DRY25 differences are $0.44,0.73,0.92$ and $1.48^{\circ} \mathrm{C}$, respectively. These findings further confirm that high-temperature short-range weather simulations are very sensitive to a decrease in the initial soil moisture. 

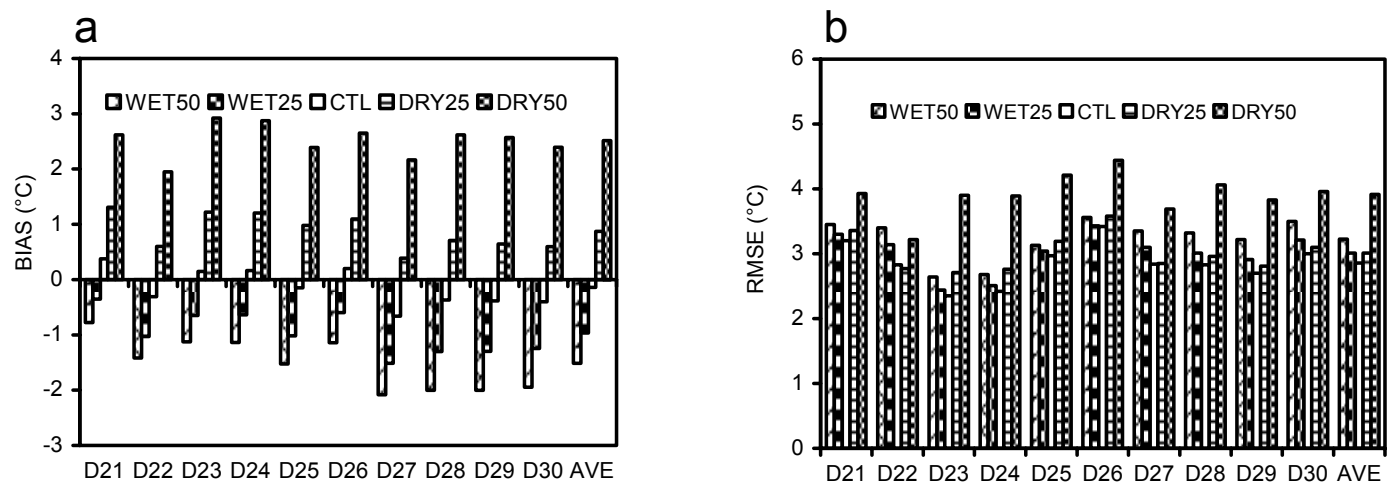

Figure 5. The BIAS (a) and RMSE (b) values for SAT06 in the individual simulations with a 10-day average (AVE).

\subsubsection{Simulation errors}

To examine the consistency of simulations with observations and to assess the sensitivity results under different soil moisture conditions, the simulation results are interpolated to meteorological stations (Fig. 1a). In the following section, the model bias (BIAS) and root mean square error (RMSE) are applied, which are computed as

$\mathrm{BIAS}=\bar{M}-\bar{O}$,

RMSE $=\sqrt{\frac{1}{N} \sum_{i=1}^{N}\left(M_{i}-O_{i}\right)^{2}}$,

where $M$ is the simulated quantity, and $O$ is the observation.

Figure 5 presents the BIAS and RMSE values for the SAT06 in each simulation. The CTL run shows a SAT06 value near the observational value, with the 10-day mean SAT06 value $0.14{ }^{\circ} \mathrm{C}$ lower than the observational value (Fig. 5a); thus, the BIAS in each sensitivity simulation is generally consistent with the SAT06 difference between the simulation and CTL. The 10-day mean SAT06 values of DRY50 and DRY25 are 2.5 and $0.90^{\circ} \mathrm{C}$ higher, respectively, than the observations, with a relative difference exceeding $150 \%$ (relative to DRY25), while the SAT06 values of WET50 and WET25 are 1.5 and $0.96^{\circ} \mathrm{C}$ lower, respectively, with a difference as high as $50 \%$ (relative to WET25). These day-to-day results further demonstrate that the high-temperature weather simulation is very sensitive to the change in soil moisture and is more sensitive at a lower level of soil moisture than at a higher level. In other words, hot weather can be amplified under low soil moisture conditions. Similar results can be observed from the RMSE values (Fig. 5b), e.g. the average RMSE values of DRY50 and DRY25 are 3.9 and $3.0^{\circ} \mathrm{C}$, respectively, i.e. the difference is large.

\subsection{Explanation of the sensitivity: details of physical processes}

Regarding the mechanism responsible for the sensitivity, the SAT difference induced by initial soil moisture is directly caused by different land surface energy fluxes and by modified regional dynamic circulation. Among the fluxes, upward sensible heat transfer directly heats the low-level atmosphere and plays a key role in influencing the SAT, while latent heat flux is modified by the change in soil moisture and evaporation, which further affect the SAT. For example, decreased soil moisture leads to lower evaporation and a reduced cooling effect of the land surface; as a result, a higher sensible heat flux is available to heat the lower troposphere.

\subsubsection{Soil moisture}

The Noah land surface scheme calculates the soil moisture for four layers with thicknesses of 10,30, 60 and $100 \mathrm{~cm}$ for the L1, L2, L3 and L4 layers, respectively. Figure 6 shows the variations of the 10-day mean soil moisture in the five groups of simulations. Overall, the changes in the soil moisture within $24 \mathrm{~h}$ are closely related to the depths of the soil layers and the initial values of the soil moisture. The shallow soil moisture changes significantly, while the deep soil moisture is less modified or nearly unchanged. Shown in Fig. 6a, the CTL soil moistures of L3 and L4 change slightly, while those of L1 and L2 decrease more due to continuous evaporation, which is consistent with the late July weather of sunny days and no rainfall. In DRY25, the surface soil moisture appears to be recharged by the lower soil layer because the surface moisture is very low (lower than that in CTL, which is normally dry), and the surface soil moisture after $24 \mathrm{~h}$ is still nearly unchanged (Fig. 6b). The DRY50 surface soil moisture is similar, but with a temporal increase (Fig. 6c). The results of WET25 and WET50 contrast those of the DRY simulations: the shallow soil moisture of the former changes significantly due to the adequate water supply during the dry, hot weather, and the model spins up with $\sim 10 \%$ decreases in surface moisture during the first hour of the integrations 

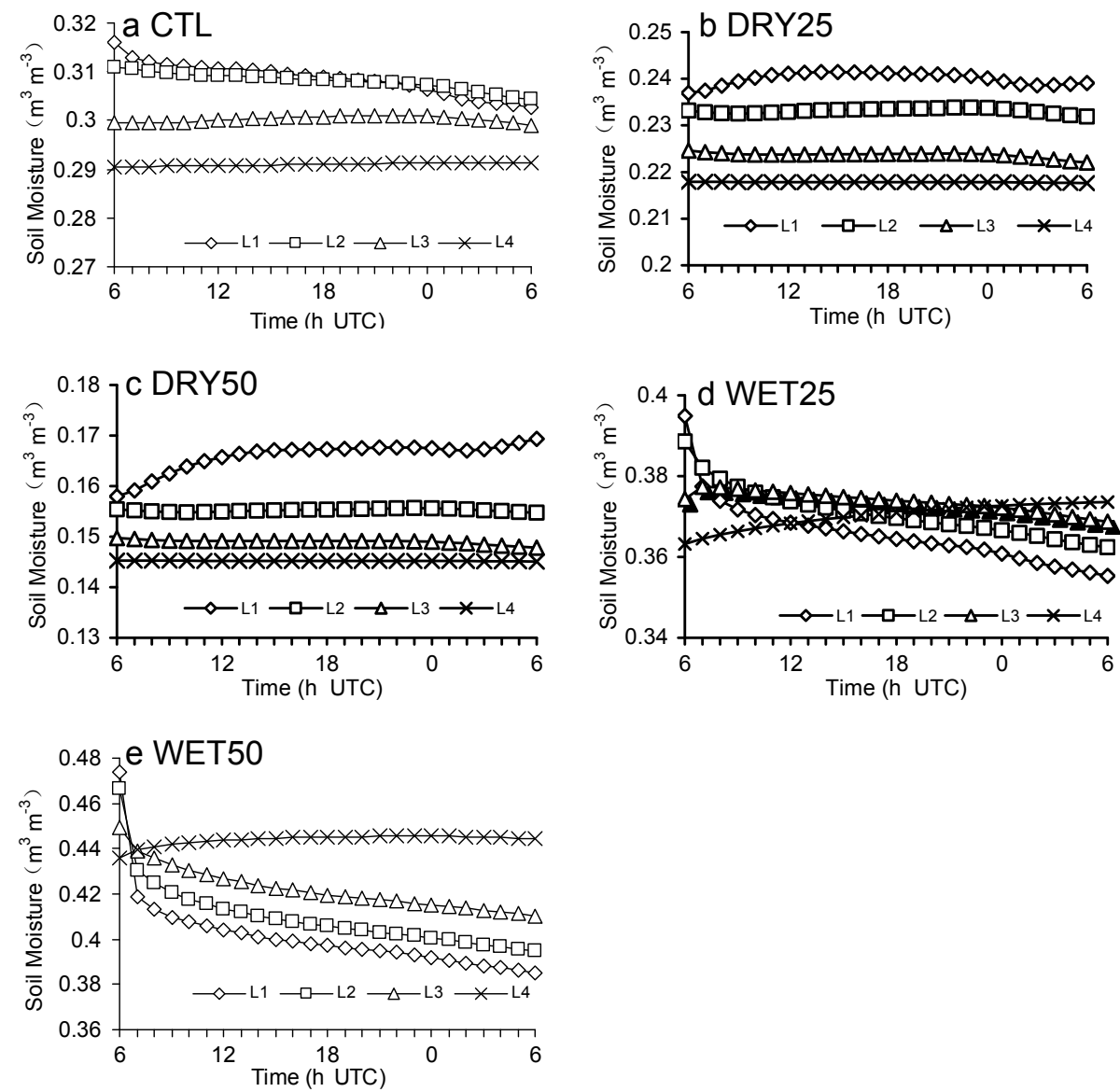

Figure 6. The mean hourly variations in soil moisture (unit: $\mathrm{m}^{3} \mathrm{~m}^{-3}$ ) in the five groups of $24 \mathrm{~h}$ simulations for 20-29 July 2003, where L1, L2, L3 and L4 represent 10, 30, 60 and $100 \mathrm{~cm}$ thick soil layers, respectively.

(Fig. 6d-e). This spin-up behaviour highlights that the initial soil moisture values should be appropriately applied to specific models in response to the model configurations.

\subsubsection{Sensible and latent heat fluxes}

Previous studies showed that surface heat transfer is crucial to changes in the atmosphere (e.g. Guo et al., 2011). Figure 7 shows the 10-day mean spatial distributions of the 06:00 UTC sensible heat flux of the simulations. Comparing Fig. 7b-e with Fig. 3g-j, the high-value area of sensible heat flux difference corresponds very well with that of the high-temperature difference, and it is also consistent with the $35^{\circ} \mathrm{C}$ or higher temperature central area, which shows that the decrease in the initial soil moisture causes the increase in sensible heat flux and thus directly leads to the temperature rise. These results indicate that sensible heat flux is a key factor for the simulated SAT06; this conclusion is consistent with previous studies. For example, the coupling of soil moisture and temperature is mainly determined by the ability of the soil moisture to affect surface fluxes (e.g. Fischer et al., 2007; Zhang et al., 2011). It also shows that, sim- ilarly to long-term (e.g. 3-month) climate simulations, shortrange $(24 \mathrm{~h})$ simulations with different soil moisture values can cause changes in surface fluxes that further affect and respond to simulated SAT results.

Corresponding to Fig. 7, Fig. 8 displays the simulated 06:00 UTC latent heat fluxes. The area with the small latent heat flux differences agrees with the area of the large sensible heat flux differences (Fig. 8b-e vs. Fig. 7b-e) and with the high-value area of the SAT06 differences (Fig. $3 g-j$ ). This result is observed because the surface latent heat flux and sensible heat flux are two components that partition the surface net radiation. Given a stable forcing of net radiation, the decrease in latent heat flux leads to the increase in sensible heat flux; thus, low-level temperatures increase and vice versa. In addition to the land surface changes, different SMOIS values that cause changes in the surface latent heat flux would also indirectly lead to changes in the SAT by modifying the radiative forcing and circulation of the atmosphere (addressed at the end of this section).

In addition to the above consistency of the overall spatial patterns of the SAT and fluxes, the hourly variations of the 10-day mean surface quantities clearly show the high 

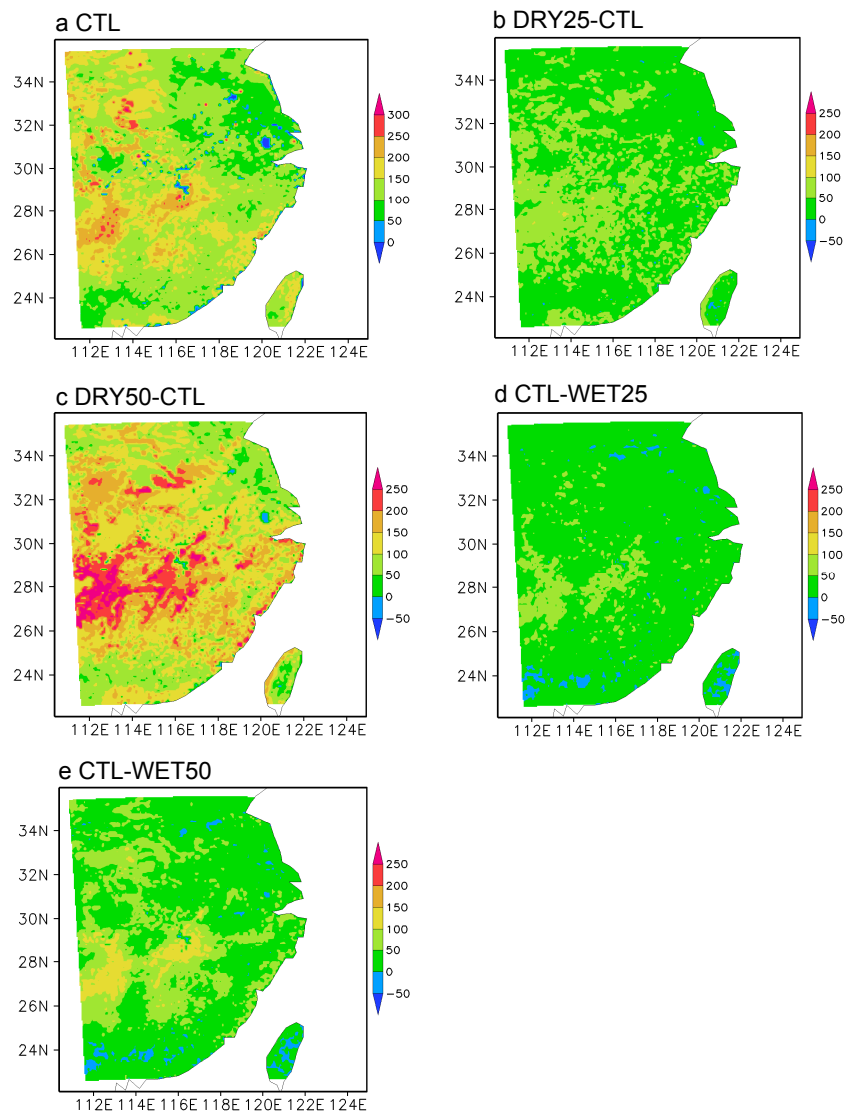

Figure 7. The spatial distributions of the 10-day mean 06:00 UTC sensible heat fluxes in the simulations (unit: $\mathrm{W} \mathrm{m}^{-2}$ ).

SMOIS-induced sensitivities (Fig. 9) during the $24 \mathrm{~h}$ periods, e.g. large flux differences appear during the daytime and peak at 04:00 UTC, while the SATs reach the maxima at 06:00 UTC. Thus, the changes in the fluxes are anterior to the SAT changes; this result is consistent with many observations in the planetary boundary layer (e.g. Liu et al., 2011).

The daily 06:00 UTC fluxes and the flux and SAT06 differences between the sensitivity simulations and CTL are shown in Fig. 10. These results not only confirm the substantial SMOIS-induced sensitivity in the context of single $24 \mathrm{~h}$ simulations (e.g. the DRY50-DRY25 sensible heat flux difference is $67 \mathrm{~W} \mathrm{~m}^{-2}$ larger than the WET50-WET25 difference, Fig. 10a, and corresponds to an SAT06 difference of approximately $1.6^{\circ} \mathrm{C}$ ) but also indicate that features of the 10 day mean quantities at 06:00 UTC are consistent with those of the 10-day means averaged with hourly values. Therefore, the high-temperature differences for 06:00 UTC may be caused by the SMOIS-induced persistent forcings during the $24 \mathrm{~h}$.

It is worth noting that while the SMOIS change is nonlinearly related to the change in the $24 \mathrm{~h}$ averaged sensible heat flux, the change in sensible heat flux essentially corre-
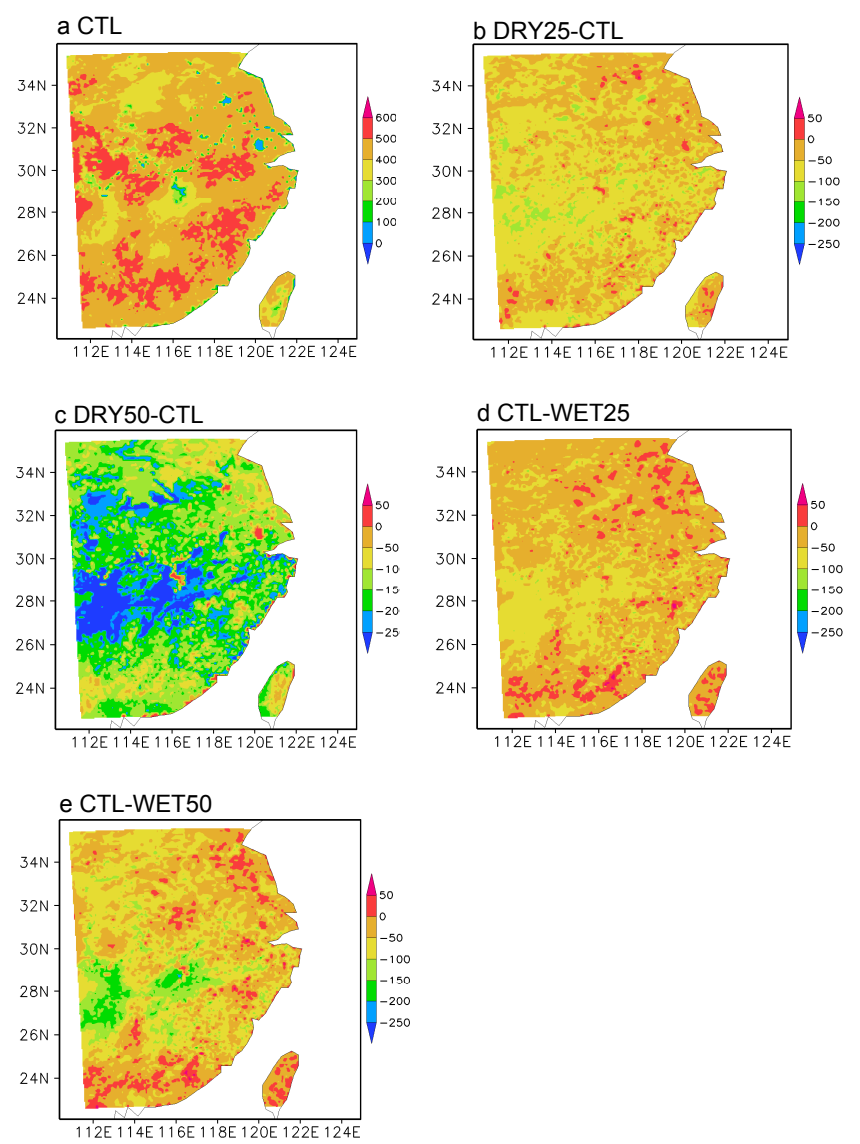

Figure 8. As Fig. 7 but for latent heat fluxes.

sponds to the SAT06 change in an approximately linear manner (Fig. 10d).

As the SMOIS changes, the modified latent heat flux has more significant and complex implications for the surface energy balance. Table 1 lists the 10-day mean 06:00 UTC values and those averaged with the hourly outputs for the surface quantities in the five groups of simulations. Interestingly, the variation of the soil moisture modifies the variation of the net radiation and leads to large differences between the change in sensible heat flux and the change in latent heat flux, i.e. the SMOIS increase results in the larger increase in latent heat flux compared to the decrease in sensible heat flux; thus, the surface net radiation increases, and vice versa. For example, the CTL daily average Bowen ratio (ratio of sensible heat to latent heat) is approximately 0.2 ; as soil moisture decreases, the Bowen ratio increases according to the $24 \mathrm{~h}$ means of approximately 0.3 and 0.8 in DRY25 and DRY50, respectively. Owing to the increase in sensible heat flux, the SAT rises. The results of the 10-day mean quantities at 06:00 UTC are similar to those of the hourly values, i.e. the surface net radiation increases with soil moisture and results in the increase in the sum of the sensible and latent heat fluxes.

The results for the surface energy balance can be understood theoretically. As reported in previous studies (e.g. 

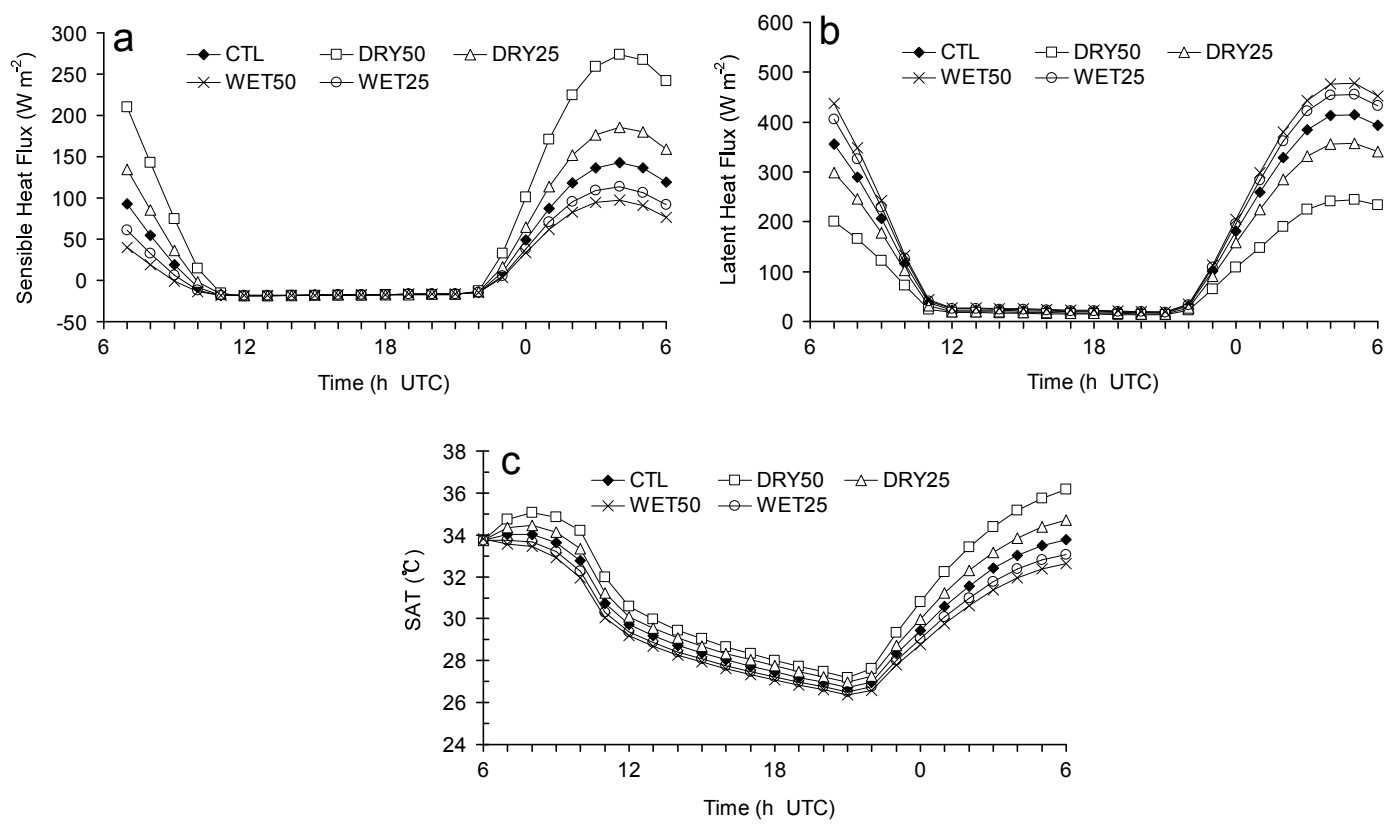

Figure 9. The mean hourly variations in the area-averaged (area D3) surface quantities for the five groups of simulations during 2029 July 2003, where the initial flux values are zero (not shown) and the initial temperatures are the same value: (a) sensible heat flux, (b) latent heat flux, (c) SAT.
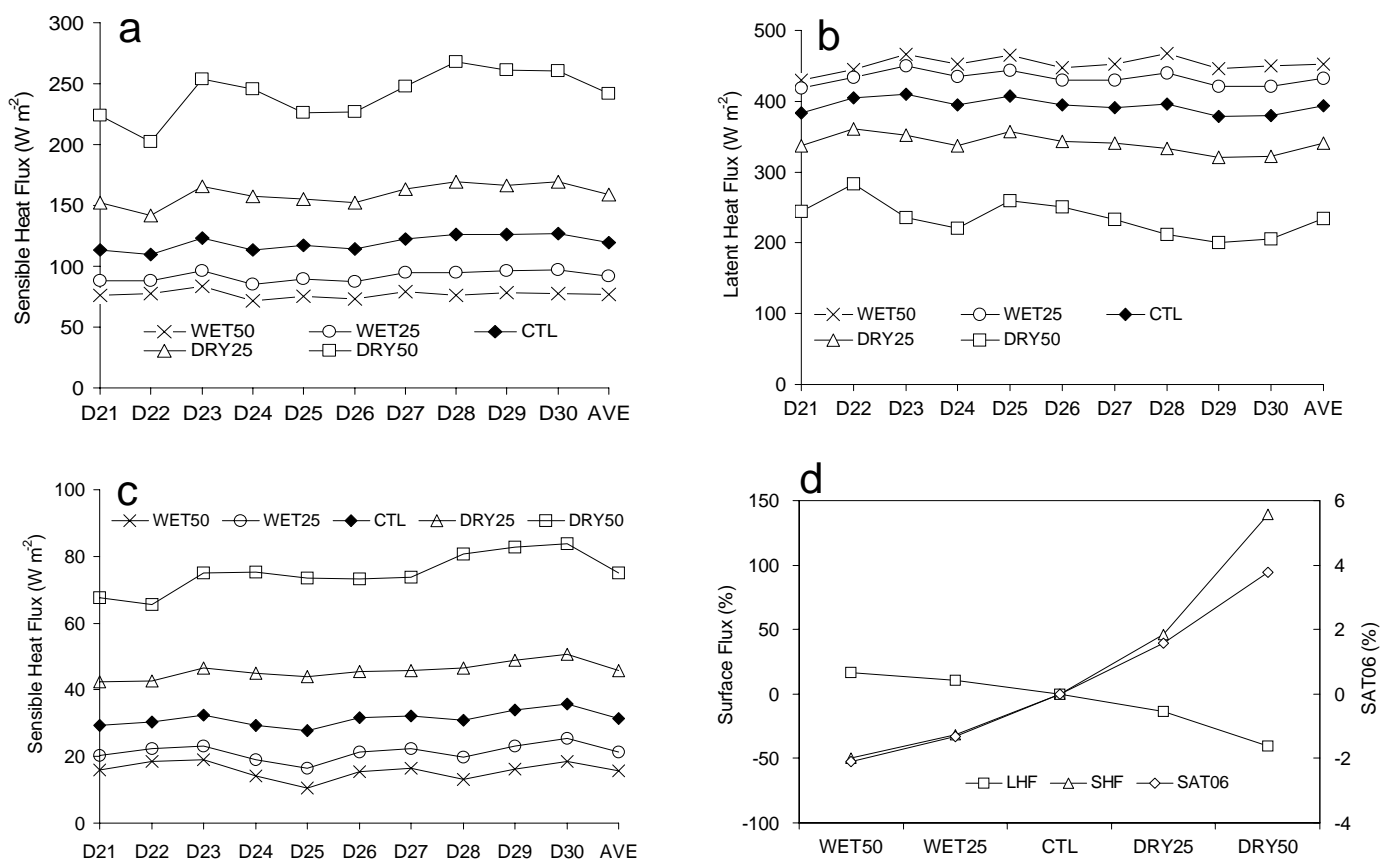

Figure 10. The area-averaged sensible and latent heat fluxes and SAT06. (a) The 06:00 UTC sensible heat flux for individual simulations with a 10-day average (AVE) for each group of simulations. (b) The same as (a) but for latent heat flux. (c) The same as (a) but for the $24 \mathrm{~h}$ mean sensible heat flux (SHF). (d) The relative differences (\%) in the 10-day mean $24 \mathrm{~h}$ averaged sensible heat flux (SHF), latent heat flux (LHF) and SAT06 compared to CTL. 
Table 1. The 10-day means of $24 \mathrm{~h}$ averaged and 06:00 UTC sensible heat flux (SHF; $\mathrm{W} \mathrm{m}^{-2}$ ), latent heat flux (LHF; W m ${ }^{-2}$ ), LHF plus $\mathrm{SHF}$, net radiation $\left(\mathrm{RN} ; \mathrm{W} \mathrm{m}^{-2}\right)$ and surface air temperatures $\left(\mathrm{SAT} ;{ }^{\circ} \mathrm{C}\right)$ for the five groups of simulations.

\begin{tabular}{|c|c|c|c|c|c|c|c|c|c|c|}
\hline & \multicolumn{2}{|r|}{ SHF } & \multicolumn{2}{|r|}{ LHF } & \multicolumn{2}{|c|}{ SHF+LHF } & \multicolumn{2}{|c|}{$\mathrm{RN}$} & \multicolumn{2}{|c|}{ SAT } \\
\hline DRY50 & 75.1 & 241.5 & 92.5 & 234.4 & 167.6 & 475.9 & 210.7 & 623.4 & 31.34 & 36.19 \\
\hline CTL & 31.4 & 119.3 & 154.7 & 393.8 & 186.1 & 513.1 & 226.0 & 658.7 & 30.21 & 33.79 \\
\hline WET25 & 21.3 & 91.7 & 170.8 & 432.1 & 192.1 & 523.8 & 230.1 & 666.8 & 29.81 & 33.06 \\
\hline WET50 & 15.8 & 76.8 & 180.1 & 452.3 & 195.9 & 529.1 & 232.2 & 670.3 & 29.57 & 32.62 \\
\hline
\end{tabular}

Baldocchi et al., 2001), the Bowen ratio of well-vegetated humid areas is generally less than 1 ; therefore, latent heat flux, other than sensible heat flux, is the primary factor that partitions net radiation at the land surface. Because of the SMOIS increase, latent heat flux (i.e. water vapour flux) increases much more, produces a stronger greenhouse effect and strengthens the downward atmospheric long-wave radiation. Further, because sunny weather persisted during the simulation period, the change in the cloud-induced reflected solar radiation was negligible. Therefore, the change in short-wave radiation, which is only slightly modified by the SMOIS-induced water evaporation, is also suggested to be very small. Hence, the SMOIS-induced pronounced change in the surface net radiative energy is largely modified by the greenhouse effect of water vapour (rather than by the short-wave radiation). For instance, from DRY 25 to CTL, the 10-day mean net radiation based on the hourly values increases by approximately $5 \mathrm{~W} \mathrm{~m}^{-2}$, which is quite large (e.g. in contrast to the sensitivity of the regional surface net radiation to deforestation in the Amazon Basin at a scale of $10^{6} \mathrm{~km}^{2}$; Dickinson and Kennedy, 1992). Additionally, the 06:00 UTC net radiation increases by approximately $12 \mathrm{~W} \mathrm{~m}^{-2}$, and the sums of the sensible and latent heat fluxes increase by similar magnitudes. However, because of the SMOIS increase, the added net radiation, which is induced by the increased ground heat flux, is still less than the decrease in the sums. Therefore, the overall effect of the SMOIS increase is cooling at the land surface.

\subsubsection{Atmospheric circulation}

The SAT variation is closely related to the changes in the regional atmospheric circulation, which is a key element of the synoptic system over the region. Regarding the atmospheric circulations in the mid-level and low-level troposphere, Figs. 11 and 12 show the 500 and $850 \mathrm{hPa}$ geopotential height fields, respectively, and the height differences caused by the SMOIS change. As stated in Sect. 2, the western Pacific subtropical high is the dominant control over the weather in continental China in summer; thus, a drop in the geopotential height at a given pressure level corresponds to a weakening of the subtropical high atmospheric
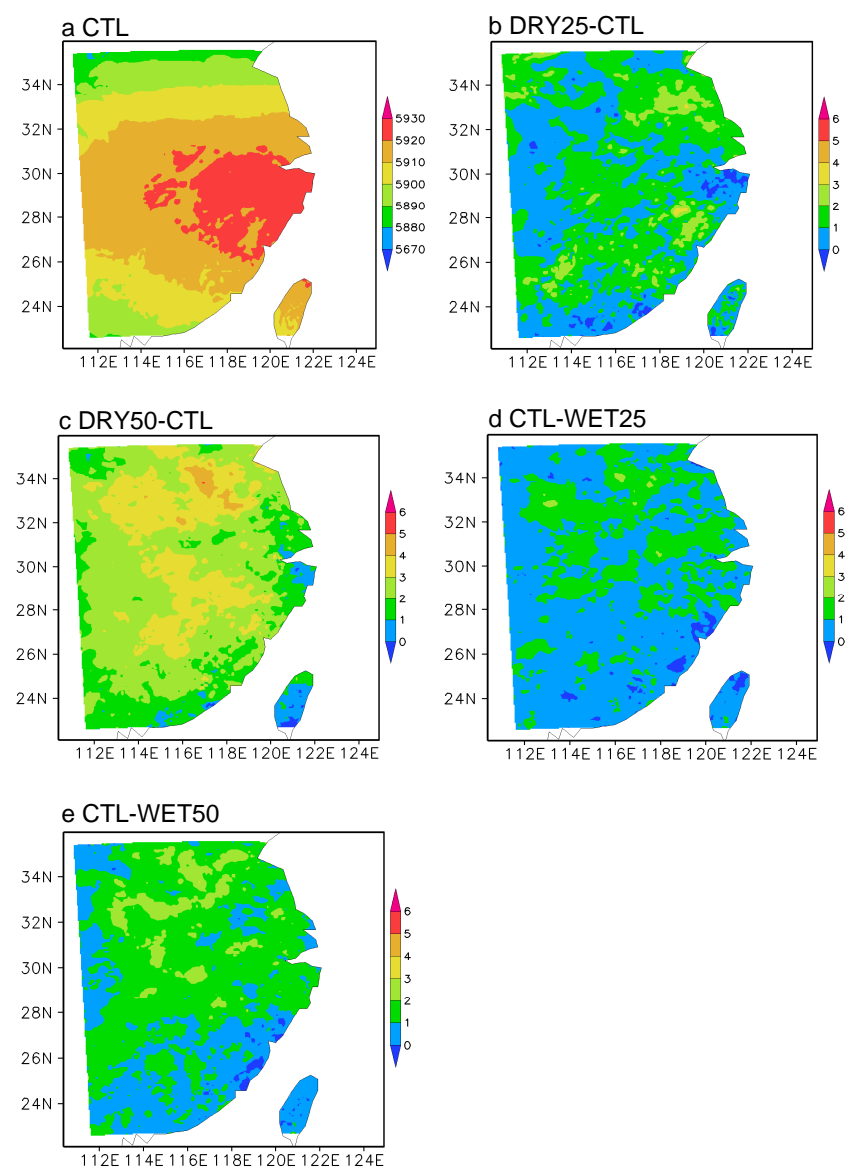

Figure 11. The 10-day mean 06:00 UTC $500 \mathrm{hPa}$ geopotential height fields and the soil moisture-induced differences in the five groups of simulations (unit: gpm).

circulation, and vice versa. Shown in Figs. 11 and 12, the weather during late July 2003 was controlled by the subtropical high, and the SMOIS decrease leads to the increase (decrease) in the $500 \mathrm{hPa}(850 \mathrm{hPa})$ geopotential heights. For example, compared to CTL, the DRY50 $500 \mathrm{hPa}$ geopotential height in the simulated area generally increases by over $2 \mathrm{gpm}$, with a maximum increase of over $4 \mathrm{gpm}$ (Fig. 11c); the soil moisture-induced effect on the $850 \mathrm{hPa}$ geopotential 

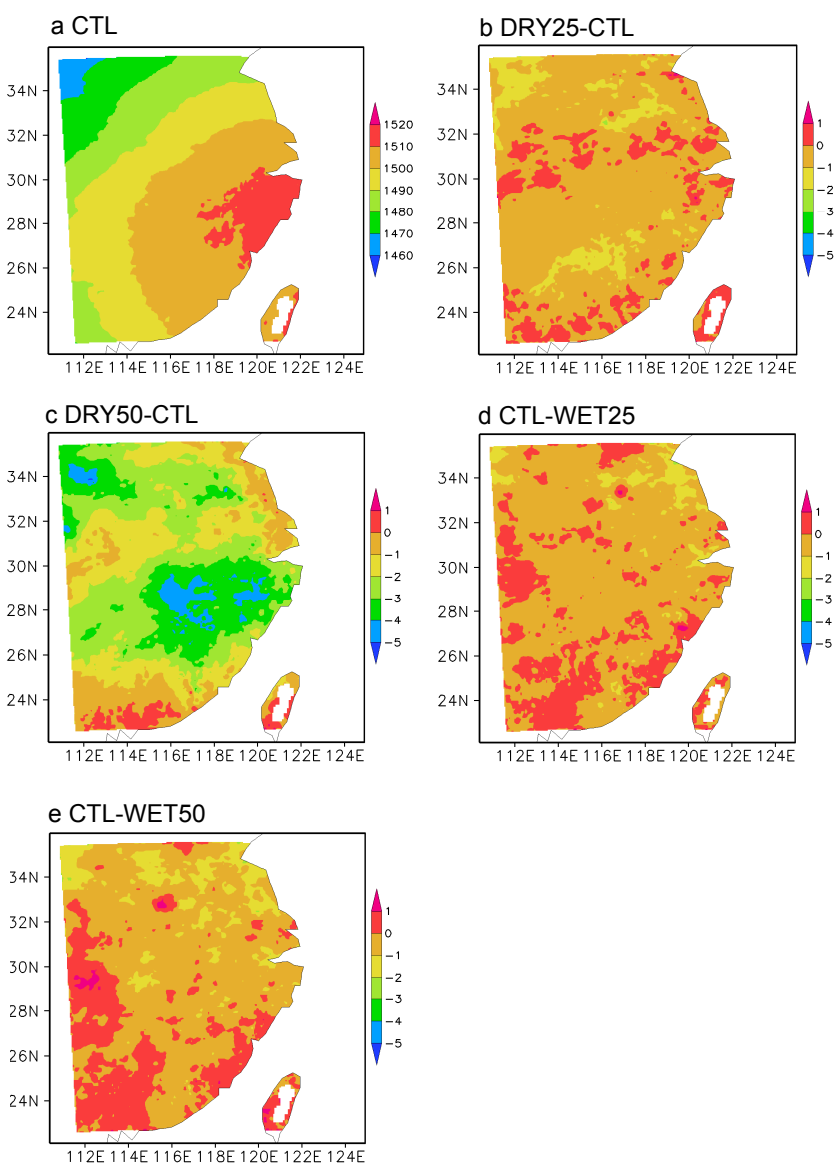

Figure 12. As Fig. 11 but for $850 \mathrm{hPa}$.

height is opposite to that at $500 \mathrm{hPa}$, i.e. the SMOIS decrease leads to reduced $850 \mathrm{hPa}$ geopotential heights in most of the simulated areas, and vice versa. Figure 13 presents the differences in the 10-day mean surface air pressure at 06:00 UTC between the groups of simulations. The SMOIS decrease appears to cause a decrease in the surface pressure, and the area with the surface pressure reduction is consistent with the area of the SAT06 increase (Fig. 13a-d vs. Fig. 3g-j). The SMOIS-induced surface pressure drop is consistent with the decrease in the $850 \mathrm{hPa}$ geopotential heights.

In previous soil moisture sensitivity experiments over North America using various climate models, Oglesby and Erickson (1989) and Pal and Eltahir (2003) found heat lows at the surface and enhanced positive height anomalies in the upper atmosphere because of reduced soil moisture. Fischer et al. (2007) conducted sensitivity experiments for the 2003 European heatwave and found a weak surface heat low and enhanced ridging in the mid-troposphere due to reduced soil moisture; they suggested that a positive feedback mechanism exists between soil moisture, continental-scale circulation and temperature. However, our results indicate a negative soil moisture-induced feedback mechanism between atmospheric circulation and temperature in the lower atmosphere in ad-
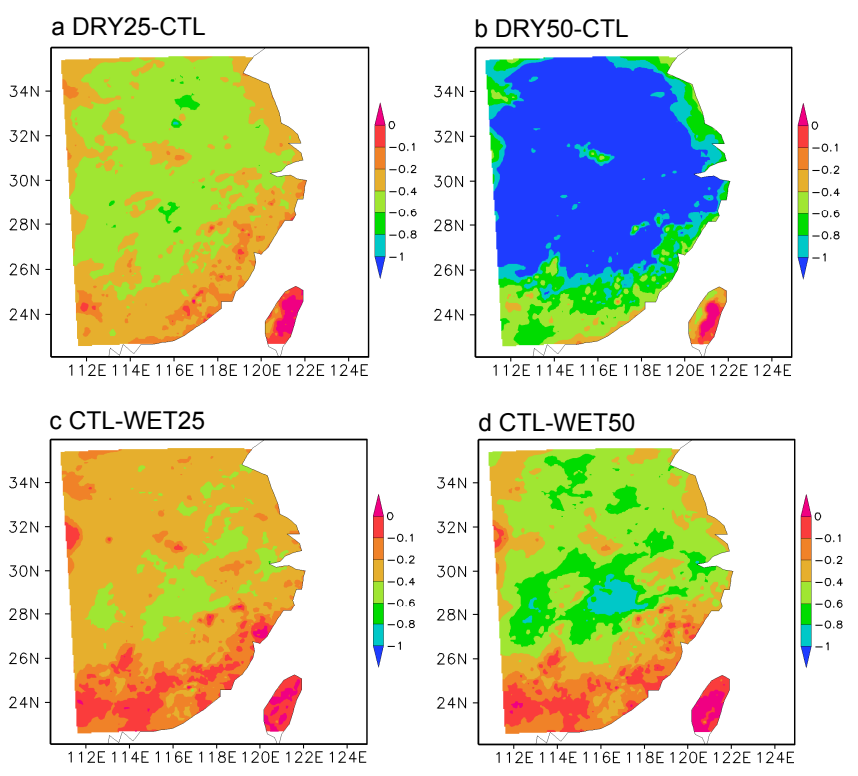

Figure 13. The 10-day mean 06:00 UTC surface pressure difference fields as compared between different groups of simulations (unit: $\mathrm{hPa}$.

dition to positive feedback in the mid-troposphere. In fact, the low-level temperature increases due to the SMOIS decrease; then, the air volume expands after being heated and causes vertical and horizontal movement. Specifically, in the vertical direction, the secondary "circulation", whose direction is opposite to the actual airflow in the lower layer of the western Pacific subtropical high, actually results in weakened low-level subsidence in the subtropical high. Along with the horizontally expanded air that causes mass divergence in the lower layer, the pressure in the lower atmosphere is thus reduced under the constraint of the hydrostatic balance. Meanwhile, the expanded air induced by the SMOIS decrease lifts the pressure levels in the middle and upper troposphere, e.g. the $500 \mathrm{hPa}$ geopotential height is enhanced (Fig. 11). The difference in the feedback mechanisms between Fischer et al. (2007) and our study is largely explained by the dynamical subtropical high, rather than a heat low, that strongly persists in the lower and upper atmosphere in East China; this is similar to the sensitivity study by Zeng et al. (2011) using different land surface schemes.

\subsubsection{Physical processes: further quantitative analysis}

As discussed in Sect. 2.3, because of the limited $2 \mathrm{~m}$ model output, all the terms for the physical processes in Eq. (2) cannot be calculated directly. The simulation results show that the variation of the air temperature $\left(T_{z 1}\right)$ at the lowest model level (i.e. $\sim 30 \mathrm{~m}$ above the ground, where the simulation results are adequate) is basically consistent with that of the air temperature at $2 \mathrm{~m}$ (i.e. SAT) in the simulations (e.g. shown in Fig. 14 for CTL). For example, both temperatures 


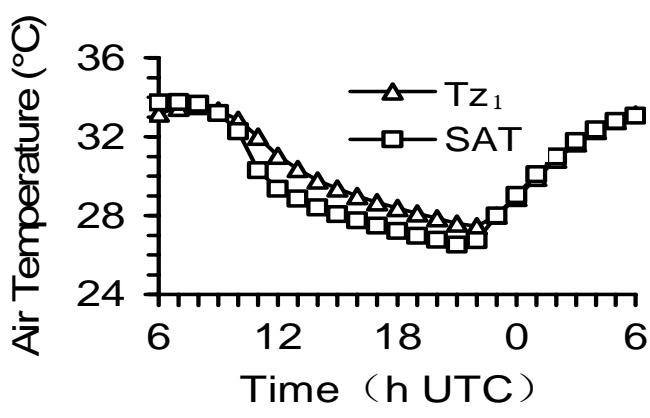

Figure 14. The mean hourly variations of $2 \mathrm{~m}$ air temperature (SAT) and the air temperature at the lowest model level $\left(T_{z 1}\right)$ in the CTL run for 20-29 July 2003.

gradually decrease with time in the afternoon, with the lowest values at approximately 21:00-22:00 UTC. Then, the temperatures rapidly rise and are maximised at approximately 06:00 UTC. The consistency in the variations demonstrates that in the near-surface layer, the mechanism influencing the $2 \mathrm{~m} \mathrm{SAT}$ is similar to that influencing $T_{z 1}$. Therefore, in this study, the advection, convection and diabatic terms in Eq. (2) are computed for the lowest model level to examine the relative importance of the terms for $T_{z 1}$. Similarly, an explanation of the mechanism for the SMOIS-induced SAT changes can be provided.

Note that the strong western Pacific subtropical high was the dominant weather system during the period, when mean subsidence prevailed. Specifically, the CON term reflects the adiabatic effect of subsidence. Table 2 lists the area-averaged 10-day mean integral results of the four terms in Eq. (2) for night-time and daytime. Although the temperature advection effect (ADV) might be relatively strong on the single-station temperature during some periods, the area-averaged ADV values, as one of the contributors to the $T_{z 1}$ change, are so small that they can be ignored in the $24 \mathrm{~h}$ simulations. For the subsidence effect term, under different soil moisture conditions, the CON values do not generally change much, especially during the daytime; one exception is for the DRY cases during night-time, which have an overall warming effect as the SMOIS decreases (e.g. compared with CTL, DRY25 produces a $0.16^{\circ} \mathrm{C}$ higher value for the CON term). A comparison of the CON term during the daytime with that during the night-time indicates that the adiabatic warming effect of the mean subsidence in the western Pacific subtropical high at night is much stronger than that in the daytime (e.g. the DRY25-CON temperature rises 11.12 and $1.01{ }^{\circ} \mathrm{C}$ in the night-time and daytime, respectively); thus, the regional atmospheric circulation may have a much more significant influence on the temperature change in the surface layer at night. The difference in the heating effect is mainly due to the stratification difference between day and night in the subtropical high, i.e. the daytime boundary layer is relatively well mixed compared to the night-time boundary layer, and mean subsidence has a greater heating influence on the hydrostatically stable lower atmosphere during the night-time than during the daytime. In addition, because the night-time subsidence effect is more affected by the SMOIS change than the nearly unchanged daytime subsidence effect, relative to the WET conditions, an enhanced temperature increase is induced under the DRY conditions at the end of the $24 \mathrm{~h}$ integrations (Table 2).

Compared with the absolute CON values for night-time and daytime, the corresponding absolute $Q_{\mathrm{t}}$ values are larger, i.e. the absolute $\mathrm{CON}$ values are approximately two thirds of the magnitude of the absolute $Q_{\mathrm{t}}$ values at night and less than one fourth of the absolute $Q_{\mathrm{t}}$ values in the daytime (Table 2). This finding indicates the dominant role of diabatic processes over the role of subsidence at the intra-daily timescales. During the night-time, with the occurrence of the boundary layer temperature inversion induced by the long-wave radiative cooling at the land surface, the turbulence-induced diabatic cooling effect is larger than the adiabatic temperature increase effect; therefore, the surface air becomes colder. During the daytime, along with the modified stratifications, diabatic heating dominates and is much stronger than the subsidence-induced adiabatic temperature increase, which is much weaker compared to the night-time. Interestingly, although the diabatic effect dominates the subsidence effect during the night-time and daytime (e.g. the night-time value is $-15.33{ }^{\circ} \mathrm{C}\left(11.01{ }^{\circ} \mathrm{C}\right)$ and the daytime value is $4.21^{\circ} \mathrm{C}$ $\left(0.99^{\circ} \mathrm{C}\right)$ for the WET25 $Q_{\mathrm{t}}(\mathrm{CON})$ term), because the $Q_{\mathrm{t}}$ term has opposite signs during the various time periods, the overall diabatic effect does not dominate the subsidence effect for the $24 \mathrm{~h}$ simulations. The diabatic effect is stronger than the subsidence effect in the CTL and WET (DRY) cases over the $24 \mathrm{~h}$, and vice versa. For instance, WET25 (DRY25) produces the values of 12.05 and $-12.76^{\circ} \mathrm{C}(12.20$ and $-11.37^{\circ} \mathrm{C}$ ) for the $24 \mathrm{~h} \mathrm{CON}$ and $Q_{\mathrm{t}}$ terms, respectively. Contrary to the CON consistent heating effect, the $Q_{\mathrm{t}}$ term has an overall cooling effect. However, it should be noted that the overall temperature rise, in response to the SMOIS decrease (e.g. the increase in the $24 \mathrm{~h} T_{\mathrm{t}}$ term compared to CTL), is mainly caused by the decreased cooling effect of the $Q_{\mathrm{t}}$ term instead of the increased heating effect of the CON term, e.g. for the $24 \mathrm{~h}$ integrations, the $T_{\mathrm{t}}$ term changes from $-0.14{ }^{\circ} \mathrm{C}$ (CTL) to $0.83^{\circ} \mathrm{C}$ (DRY25), and the change is accompanied by a difference in the CON term (from 12.04 to $12.20^{\circ} \mathrm{C}$ ) and a much larger difference in the $Q_{\mathrm{t}}$ term (from -12.18 to $-11.37^{\circ} \mathrm{C}$ ). These results demonstrate that the overall diabatic processes are affected much more strongly by the SMOIS change. A closer comparison shows that this sensitivity is higher under the DRY conditions (Table 2), as is consistent with the sensitivity findings for SAT06 in Sect. 3.

In the 12-day simulations of warm-season convection, Trier et al. (2008) suggested that the initial soil moisture had an important influence on thermodynamic variables, particularly when the ground heating is the strongest in the daytime and the subsequent period. Our results confirm this issue and 
Table 2. Area-averaged 10-day mean integral results of the four terms in the $T_{z 1}$ equation (i.e. Eq. 2) for 24 h, night-time (11:00-22:00 UTC) and daytime (22:00-06:00 UTC) (unit: ${ }^{\circ} \mathrm{C}$ ). Note that the daytime is divided into two periods (by the night hours) in the $24 \mathrm{~h}$ integrations, and only one part, which is assumed to be reasonable and have little influence on the analysis, is considered in the statistics.

\begin{tabular}{|c|c|c|c|c|c|c|c|c|c|c|c|c|}
\hline & \multicolumn{3}{|c|}{$T_{\mathrm{t}}$} & \multicolumn{3}{|c|}{$\mathrm{ADV}$} & \multicolumn{3}{|c|}{$\mathrm{CON}$} & \multicolumn{3}{|c|}{$Q_{\mathrm{t}}$} \\
\hline & $24 \mathrm{~h}$ & Night-time & Daytime & $24 \mathrm{~h}$ & Night-time & Daytime & $24 \mathrm{~h}$ & Night-time & Daytime & $24 \mathrm{~h}$ & Night-time & Daytime \\
\hline DRY50 & 2.22 & -5.12 & 7.37 & $-2.6 \times 10^{-5}$ & $-1.2 \times 10^{-5}$ & $4.4 \times 10^{-5}$ & 12.60 & 11.42 & 1.01 & -10.38 & -16.54 & 6.34 \\
\hline DRY25 & 0.83 & -4.70 & 6.24 & $6.2 \times 10^{-5}$ & $2.8 \times 10^{-5}$ & $1.6 \times 10^{-5}$ & 12.20 & 11.12 & 1.01 & -11.37 & -15.72 & 5.24 \\
\hline CTL & -0.14 & -4.51 & 5.66 & $-1.8 \times 10^{-5}$ & $-4.9 \times 10^{-6}$ & $2.7 \times 10^{-6}$ & 12.04 & 10.91 & 0.98 & -12.18 & -15.42 & 4.67 \\
\hline WET25 & -0.71 & -4.32 & 5.20 & $-1.8 \times 10^{-4}$ & $3.0 \times 10^{-5}$ & $-2.1 \times 10^{-4}$ & 12.05 & 11.01 & 0.99 & -12.76 & -15.33 & 4.21 \\
\hline WET50 & -1.20 & -4.24 & 4.92 & $1.0 \times 10^{-4}$ & $1.2 \times 10^{-4}$ & $-3.0 \times 10^{-5}$ & 12.01 & 11.06 & 0.98 & -13.21 & -15.30 & 3.94 \\
\hline
\end{tabular}

also show that the SMOIS-induced change in the night-time cooling can exceed half of the change in the daytime heating in the high-temperature simulations (e.g. from CTL to DRY25, the $Q_{\mathrm{t}}$ term decreases by $0.30^{\circ} \mathrm{C}$ during the nighttime and increases by $0.57^{\circ} \mathrm{C}$ during the daytime; Table 2).

Similarly, subsidence and diabatic processes play important roles in modifying the $2 \mathrm{~m}$ air temperature (SAT) change, in which the diabatic processes dominate the adiabatic subsidence during the daytime and night-time in the subtropical high. Additionally, the diabatic effect on the SAT variation is affected more strongly by the soil moisture change, e.g. with the SMOIS decrease, the SAT tends to increase, mainly because of the decreased cooling effect of the diabatic processes in the $24 \mathrm{~h}$ integrations. Because of the dry climate background in East China in late July 2003, sensible heat flux played a dominant role in modifying the SAT among the lowlevel diabatic processes, such as sensible and latent heating and radiation processes. Therefore, primarily through modifying the surface sensible heat flux, the initial soil moisture affects the simulation of extremely high temperatures in late July 2003 in East China.

Notably, when only CTL is taken into account, during late July, the diabatic processes are slightly more important than mean subsidence over the region (i.e. the sign of the SAT change is opposite of the subsidence term during the $24 \mathrm{~h}$ periods in CTL; Table 2). This shows the relative importance of physical processes in the hottest phase. For periods with lower temperatures, the values of both the diabatic and subsidence terms are reduced. Given invariant signs for both, it is unlikely to pinpoint which term would dominate using a theoretical analysis only; thus, follow-up numerical studies are needed for other cases.

\section{Summary and conclusions}

This paper quantifies and explains the sensitivity of WRFsimulated high-temperature weather to various initial soil moisture (SMOIS) conditions in a $24 \mathrm{~h}$ period. Five groups of simulations are conducted in the East China for an extreme high-temperature event in late July 2003.
We focus on SAT06, which is approximately the daily maximum temperature in East China. The 10-day mean results indicate that CTL can generally reproduce the hightemperature event. However, the simulated event is also sensitive to the SMOIS changes. When the SMOIS is decreased, the central position of the high SAT06 values does not change much, while the maximum SAT06 change mainly occurs over the areas with temperatures above $35^{\circ} \mathrm{C}$, which is accompanied by the temperature increase and the enlarged areas with the high temperatures. Compared with CTL, DRY25 (DRY50) results in a $1^{\circ} \mathrm{C}\left(2^{\circ} \mathrm{C}\right)$ SAT06 increase, in general, over land in East China; the low soil moisture amplifies the high temperatures in the simulations.

The modified SMOIS changes the surface fluxes and atmospheric circulation, which play different roles in modifying the SAT06. Sensible heat fluxes directly heat the lower atmosphere and present difference fields that are consistent with those of SAT06. Therefore, the SMOIS-induced sensible heat flux change could be the most significant factor in the SAT06 change. Low soil moisture can reduce evaporation such that the land surface temperature increases more easily; therefore, downward long-wave radiation and sensible heat flux can increase, and the lower atmosphere is likely to be heated. The SMOIS increase is found to modify the partitioning between sensible and latent heat fluxes. Specifically, the increased magnitude of latent heat flux is larger than the decreased magnitude of sensible heat flux. With the increase in the latent heat (evaporation), the greenhouse effect induced by water vapour is reinforced. The result is an enhanced surface net radiation, e.g. from DRY25 to CTL, the net radiation increases by $5 \mathrm{~W} \mathrm{~m}^{-2}$.

Overall, a SMOIS-induced negative feedback exists in the lower layer between the low-level temperature and the circulation, while positive feedback exists in the mid-troposphere, e.g. the low-level SAT increases due to the SMOIS decrease, the geopotential heights lower and the subtropical high in the lower atmosphere weakens, and vice versa.

Finally, we adopt an analogous relationship between the air temperature at the lowest model level and the $2 \mathrm{~m}$ air temperature (SAT) to explain how the initial soil moisture influences the simulated SAT via different processes. The results suggest that the diabatic processes dominate the adiabatic subsidence regarding the SAT changes in the WET and 
CTL simulations; the diabatic processes are affected more strongly by the SMOIS changes in all the simulations. Although the diabatic processes have opposite effects during different time periods (i.e. heating and cooling during the daytime and night-time, respectively), they have an overall cooling effect on the SAT in the $24 \mathrm{~h}$ simulations. Interestingly, although the diabatic processes dominate over subsidence during the daytime and night-time, they are not necessarily dominant during the $24 \mathrm{~h}$ periods.

Additionally, we should note that this sensitivity study is implemented using a regional weather model whose performance is affected by initial and boundary conditions and model setups. For follow-up studies, using more cases and adopting more suites of model settings to explore soil moisture effects would help us better understand the issue of soilmoisture-induced sensitivity of high-temperature/heatwave events.

Acknowledgements. The authors would like to thank W. Lu and two anonymous reviewers for their helpful comments on the paper. This work was supported by the National Natural Science Foundation of China (Grant Nos. 41275012 and 41205073).

Edited by: M. Kulmala

\section{References}

Baldocchi, D., Falge, E., Gu, L., Olson, R., Hollinger, D., Running, S., Anthoni, P., Bernhofer, C., Davis, K., Evans, R., Fuentes, J., Goldstein, A., Katul, G., Law, B., Lee, X., Malhi, Y., Meyers, T., Munger, W., Oechel, W., Paw U, K. T., Pilegaard, K., Schmid, H. P., Valentini, R., Verma, S., Vesala, T., Wilson, K., and Wofsy, S.: FLUXNET: A new tool to study the temporal and spatial variability of ecosystem - scale carbon dioxide, water vapor, and energy flux densities, B. Am. Meteorol. Soc., 82, 2415-2434, 2001.

Barriopedro, D., Fischer, E. M., Luterbacher J., Trigol, R. M., and Garcia-Herrerad, R.: The hot summer of 2010: Redrawing the temperature record map of Europe, Science, 332, doi:10.1126/science.1201224, 220-224, 2011.

Beljaars, A. C. M., Viterbo, P., Miller, M. J., and Betts, A. K.: The anomalous rainfall over the United States during July 1993: Sensitivity to land surface parameterization and soil moisture, Mon. Weather Rev., 124, 362-383, 1996.

Chen, F. and Dudhia, J.: Coupling an advanced land-surface hydrology model with the Penn State-NCAR MM5 modeling system. Part I: Model description and implementation, Mon. Weather. Rev., 129, 569-585, 2001.

Chou, M. D. and Suarez, M. J.: An efficient thermal infrared radiation parameterization for use in general circulation models, NASA Tech. Memo., 104606, 3, 85 pp., 1994.

Dickinson, R. E. and Kennedy, P.: Impacts on regional climate of Amazon deforestation, Geophys. Res. Lett., 19, 1947-1950, 1992.

Donat, M. G., Alexander, L. V., Yang, H., Durre, I., Vose, R., and Caesar, J.: Global land-based datasets for monitoring climatic extreme, B. Am. Meteorol. Soc., 94, 997-1006, 2013.
Douville, H.: Relative contribution of soil moisture and snow mass to seasonal climate predictability: A pilot study, Clim. Dynam., 34, 797-818, 2010.

Ek, M. B., Mitchell, K. E., Lin Y., Rogers, E., Grunmann, P., Koren, V., Gayno, G., and Tarpley, J. D.: Implementation of Noah land surface model advances in the National Centers for Environmental Prediction operational Mesoscale Eta Model, J. Geophys. Res., 108, 8851, doi:10.1029/2002JD003296, 2003.

Fennessy, M. J. and Kinter, J. L.: Climatic Feedbacks during the 2003 European heat wave, J. Climate, 24, 5953-5967, 2011.

Fennessy, M. J. and Shukla, J.: Impact of initial soil wetness on seasonal atmospheric prediction, J. Climate, 12, 3167-3180, 1999.

Ferranti, L. and Viterbo, P.: The European summer of 2003: Sensitivity to soil water initial conditions, J. Climate, 19, 3659-3680, 2006.

Fischer, E. M., Seneviratne, S. I., Vidale, P. L., Lüthi, D., and Schär, C.: Soil moisture - atmosphere interactions during the $2003 \mathrm{Eu}-$ ropean summer heat wave, J. Climate, 20, 5081-5099, 2007.

Guo, Z., Dirmeyer, P. A., and DelSole, T.: Land surface impacts on subseasonal and seasonal predictability, Geophys. Res. Lett., 38, L24812, doi:10.1029/2011GL049945, 2011.

Guo, Z., Dirmeyer, P. A., DelSole, T., and Koster, R. D.: Rebound in atmospheric predictability and the role of the land surface, J. Climate, 25, 4744-4749, 2012.

Hirschi, M., Seneviratne, S. I., Alexandrov, V., Boberg, F., Boroneant, C., Christensen, O. B., Formayer, H., Orlowsky, B., and Stepanek, P.: Observational evidence for soil-moisture impact on hot extremes in southeastern Europe, Nat. Geosci., 4, 17-21, 2011.

Holt, T., Niyogi, D., Chen, F., LeMone, M. A., Manning, K., and Qureshi, A. L.: Effect of Land-Atmosphere Interactions on the IHOP 24-25 May 2002 Convection Case, Mon. Weather Rev., 134, 113-133, 2006.

Hong, S.-Y. and Pan, H.-L.: Nonlocal boundary layer vertical diffusion in a medium-range forecast model, Mon. Weather Rev., 124, 2322-2339, 1996.

Hong, S.-Y., Noh, Y., and Dudhia, J.: A new vertical diffusion package with an explicit treatment of entrainment processes, Mon. Weather Rev., 134, 2318-2341, doi:10.1175/MWR3199.1, 2006.

Janjic, Z. I.: The step-mountain Eta coordinate model: Further developments of the convection, viscous sub-layer and turbulence closure schemes, Mon. Weather Rev., 122, 927-945, 1994.

Kalkstein, L. S., Jamason, P. F., Greene, J. S., Libby, J., and Robinson, L.: The Philadelphia hot weather-health watch/warning system: Development and application, summer 1995, B. Am. Meteorol. Soc., 77, 1519-1528, 1996.

Koster, R. D., Dirmeyer, P. A., Guo, Z., Bonan, G., Chan, E., Cox, P., Gordon, C. T., Kanae, S., Kowalczyk, E., Lawrence, D., Liu, P., Lu. C. H., Malyshev, S., McAvaney, B., Mitchell, K., Mocko, D., Oki, T., Oleson, K., Pitman, A., Sud, Y. C., Taylor, C. M., Verseghy, D., Vasic, R., Xue, Y., and Yamada, T.: Regions of strong coupling between soil moisture and precipitation, Science, 305, 1138-1141, 2004.

Koster, R. D., Sud, Y. C., Guo, Z., Dirmeyer, P. A., Bonan, G., Oleson, K. W., Chan, E., Verseghy, D., Cox, P., Davies, H., Kowalczyk, E., Gordon, C. T., Kanae, S., Lawrence, D., Liu, P., Mocko, D., Lu, C.-H., Mitchell, K, Malyshev, S., McAvaney, B., Oki, T., Yamada, T., Pitman, A., Taylor, C. M., Vasic, R., and Xue, Y.: 
GLACE: The Global Land-Atmosphere Coupling Experiment. Part I: Overview, J. Hydrometeor., 7, 590-610, 2006.

Larsen, J.: Record heat wave in Europe takes 35000 lives, Earth Policy Institute, Place: 1350 Connecticut Avenue NW, Suite 403, Washington, DC 20036, p. 1, 2003.

Lau, W. K. M. and Kim, K.-M.: The 2010 Pakistan flood and Russian heat wave: Teleconnection of hydrometeorological extremes, J. Hydrometeor., 13, 392-403, 2012.

Lei, M., Niyogi, D., Kishtawal, C., Pielke Sr., R. A., BeltránPrzekurat, A., Nobis, T. E., and Vaidya, S. S.: Effect of explicit urban land surface representation on the simulation of the 26 July 2005 heavy rain event over Mumbai, India, Atmos. Chem. Phys., 8, 5975-5995, doi:10.5194/acp-8-5975-2008, 2008.

Lin, J., Bi, B. G., and He, J. H.: Physical mechanism responsible for western Pacific subtropical high variation and hot wave in southern China in July 2003, Chinese J. Atmos. Sci., 29, 594 599, 2005 (in Chinese).

Lin, Y.-L., Farley, R. D., and Orville, H. D.: Bulk parameterization of the snow field in a cloud model, J. Clim. Appl. Meteorol., 22, 1065-1092, 1983.

Liu, H., Blanken, P. D., Weidinger, T., Nordbo, A., and Vesala, T.: Variability in cold front activities modulating cool-season evaporation from a southern inland water in the USA, Environ. Res. Lett., 6, 024022, doi:10.1088/1748-9326/6/2/024022, 2011.

Lyon, B. and Dole, R. M.: A diagnostic comparison of the 1980 and 1988 US summer heat wave-droughts, J. Climate, 8, 1658-1675, 1995.

Mlawer, E. J., Taubman, S. J., Brown, P. D., Iacono, M. J., and Clough, S. A.: Radiative transfer for inhomogeneous atmosphere: RRTM, a validated correlated-k model for the long-wave, J. Geophys. Res., 102, 16663-16682, doi:10.1029/97JD00237, 1997.

Oglesby, R. J. and Erickson, D.: Soil moisture and the persistence of North American drought, J. Climate, 2, 1362-1380, 1989.

Pal, J. S. and Eltahir, E. A. B.: A feedback mechanism between soil moisture distribution and storm tracks, Q. J. Roy. Meteor. Soc., 129, 2279-2297, 2003.

Pielke, R. A.: Influence of the spatial distribution of vegetation and soils on the prediction of cumulus convective rainfall, Rev. Geophys., 39, 151-177, 2001.

Seneviratne, S. I., Koster, R. D., Guo, Z., Dirmeyer, P. A., Kowalczyk, E., Lawrence, D., Liu, P., Lu, C.-H., Mocko, D., Oleson, K. W., and Verseghy, D.: Soil moisture memory in AGCM simulations: Analysis of Global Land-Atmosphere Coupling Experiment (GLACE) data, J. Hydrometeor., 7, 1090-1112, 2006.

Shukla, J. and Mintz, Y.: Influence of the land-surface evapotransporation on the Earth's climate, Science, 215, 1498-1500, 1982.

Skamarock, W. C., Klemp, J., Dudhia, J., Gill, D. O., Barker, D. M., Duda, M. G., Huang, X. Y., Wang, W., and Powers, J. G.: A Description of the Advanced Research WRF Version 3, NCAR Technical note NCARTN-475+STR, Natl. Cent. for Atmos. Res., Boulder, CO, USA, 113 pp., 2008.

Stefanon, M., D'Andrea, F., and Drobinski, P.: Heatwave classification over Europe and the Mediterranean region, Environ. Res. Lett., 7, 014023, doi:10.1088/1748-9326/7/1/014023, 2012.
Sun, J., Trier, S. B., Xiao, Q., Weisman, M. L., Wang, H., Ying, Z., Xu, M., and Zhang, Y.: Sensitivity of 0-12 h warm-season precipitation forecasts over the central United States to model initialization, Weather Forecast., 27, 832-855, 2012.

Tan, J., Zheng, Y., and Song, G.: Heat wave impacts on mortality in Shanghai, 1998 and 2003, Int. J. Biometeorol., 51, 193-200, 2007.

Trier, S. B., Chen, F., and Manning K. W.: Sensitivity of the PBL and precipitation in 12-day simulations of warm-season convection using different land surface model and soil wetness conditions, Mon. Weather Rev., 136, 2321-2343, 2008.

Viterbo, P. and Betts, A. K.: Impact of the ECMWF reanalysis soil water on forecasts of the July 1993 Mississippi flood, J. Geophys. Res., 19, 361-366, 1999.

Vinnikov, K. Y. and Yeserkepova, I. B.: Soil moisture: Empirical data and model results, J. Climate, 4, 66-79, 1990.

Whitaker, J. S., Hamill, T. M., Wei, X., Song, Y., and Toth, Z.: Ensemble data assimilation with the NCEP Global Forecast System, Mon. Weather Rev., 136, 463-482, 2008.

Willmott, C. J., Matsuura, K., and Legates, D. L.: Global air temperature and precipitation: Regridded monthly and annual climatologies (Version 2.01), available at: http://climate.geog.udel. edu/ (last access: 6 May 2014), 1998.

Wolfson, N., Atlas, R., and Sud, Y. C.: Numerical experiments related to the summer 1980 US heat wave, Mon. Weather Rev., 115, 1345-1357, 1987.

World Meteorological Organization: The Global Climate 20012010: A decade of climate extremes - Summary Report, WMONo. 1119, 2013.

Xue, Y., Zeng, F. J., Mitchell, K. E., Janjic, Z., and Rogers, E.: The impact of land surface processes on simulations of the US hydrological cycle: A case study of the 1993 flood using the SSiB land surface model in the NCEP Eta regional model, Mon. Weather Rev., 129, 2833-2860, 2001.

Yang, H. and Li, C. Y.: Diagnostic study of serious high temperature over South China in 2003 summer, Climatic and Environmental Research, 10, 81-85, 2005 (in Chinese).

Zeng, X.-M., Zhao, M., Su, B., Tang, J., Zheng, Y., Zhang, Y., and Chen, J.: Effects of the land-surface heterogeneities in temperature and moisture from the "combined approach" on regional climate: A sensitivity study, Global Planet. Change, 37, 247-263, 2003.

Zeng, X.-M., Wu, Z.-H., Xiong, S.-Y., Song, S., Zheng, Y.-Q., and Liu, H.-Q.: Sensitivity of simulated short-range high-temperature weather to land surface schemes by WRF, Science China: Earth Sciences, 54, 581-590, doi:10.1007/s11430-011-4181-6, 2011.

Zhang, J. and Wu, L.: Land-atmosphere coupling amplifies hot extremes over China, Chinese Sci. Bull., 56, 581-590, doi:10.1007/s11434-011-4628-3, 2011.

Zhang, S., Zhang, D., Wang, S., and Song, Y.: Climatic characteristics of summer high temperature and assessment methods in the large cities of North China, J. Geogr. Sci., 16, 13-22, 2006. 